\title{
Study on the Stability of Surrounding Rock of Underground Circular Cavern Based on the Anchor Reinforcement Effect
}

\author{
Shuancheng Gu, Pan Zhou (D), Wei Sun, Chunhui Hu, Zhi Li, and Chao Wang \\ School of Architecture and Civil Engineering, Xi'an University of Science and Technology, Xi'an, Shaanxi 710054, China \\ Correspondence should be addressed to Pan Zhou; zhoupan0201@163.com
}

Received 12 August 2018; Revised 13 November 2018; Accepted 21 November 2018; Published 12 December 2018

Guest Editor: Guang Xu

Copyright (c) 2018 Shuancheng Gu et al. This is an open access article distributed under the Creative Commons Attribution License, which permits unrestricted use, distribution, and reproduction in any medium, provided the original work is properly cited.

\begin{abstract}
Achieving a comprehensive and accurate understanding of the anchor reinforcement mechanism and a quantitative evaluation of the surrounding rock's stability for an anchored underground cavern can provide an important theoretical basis for supporting and excavating the cavern. First, the composite bearing structure composed of the anchor and surrounding rock was defined as the surrounding rock reinforcement body by using the homogenization method, and a new method for evaluating the stability of surrounding rock by the surrounding rock reinforcement body deformation and damage degree was proposed. Second, based on the anchor reinforcement effect, the expression of the physical-mechanical parameters of the surrounding rock reinforcement body was deduced, and the analytical solution of stress and displacement of the surrounding rock reinforcement body was obtained. Finally, the stability coefficient of surrounding rock indicating the degree of the surrounding rock reinforcement body damage was defined. The research showed that the theoretical solution agreed well with the results of the numerical simulation, and the difference between the theoretical solution and the monitoring value was less than $10 \%$, which verified the reliability of the method and the results of this paper. The design of the length and spacing of the anchor followed the principle of long but sparse and short but dense, and the pretightening force of the anchor and the stability coefficient of surrounding rock varied linearly. The analytical solution of this paper provides a theoretical reference for understanding the mechanism of anchor support and provides a quantitative evaluation method for the stability of surrounding rock. Compared with the traditional support design, the theory of this paper gives full play to the self-stability of the surrounding rock and the strength of the anchor, which is conducive to saving support costs and avoiding the construction limitations in some projects.
\end{abstract}

\section{Introduction}

With the rapid development of infrastructure construction in China, a large number of underground projects have been built in various fields, such as hydropower, civil engineering, and mining. The stability of surrounding rock in an underground cavern is the key to the construction of large-scale underground projects, and the anchor support is an important means of ensuring the stability of the underground cavern. The wholly grouted anchor constrains surrounding rock deformation through its own stiffness, strength, and transferring stress by anchoring interfaces, such as a mortar or resin anchoring agent, which strengthens the rock mass, and has been widely used in the field of geotechnical engineering [1]. Therefore, the support mechanism, the support parameter design of the wholly grouted anchor, and rock formation control are intense areas of research in underground engineering.

To study the mechanical effects of the wholly grouted anchor support, several studies have been conducted through theoretical analyses, numerical simulations, and experimental means. Freeman proposed the neutral point theory by observing the stress process of the anchor and the distribution of the stress along the anchor length [2]. Based on the neutral point theory, the force mechanisms of a wholly grouted anchor in a tunnel were studied, and the theoretical solutions of the axial force and shear stress distribution along the anchor length were derived [3-6]. The hyperbolic function model, the trifold line model, the exponential curve model, and the composite exponentialhyperbolic shear-slip model of the shear stress and shear displacement of the anchor interface have all been proposed, 
the analytical solution of the shear stress distribution at the anchor interface of the anchorage section has been derived, and the entire historical characteristics of the load transfer of the anchor at the anchorage section were simulated [7-10]. In recent years, with the development of the depth and breadth of underground cavern excavation, the anchor support has gradually developed towards a strong, highprestressed anchor support system with a high strength, high rigidity, and high reliability. To give full play to the strength of the anchor and reveal the prestressed anchoring mechanism, the relationships among the axial stress, shear stress, and preload of the anchor were analyzed via theoretical analyses and field measurements, and the distribution law of the axial stress and the shear stress of the anchor was obtained [11-13]. A deeper understanding of the coupling mechanical effect between a wholly grouted anchor and surrounding rock was achieved: the wholly grouted anchor was used to constrain surrounding rock deformation through the shear force transmitted by the interface layer, the support force of the wholly grouted anchor to the surrounding rock was equivalent to the additional volume force acting on the surrounding rock of the circular cavern, and the analytical solution of the stress and the displacement of the surrounding rock of the circular cavern under the support of the anchor was obtained [14-16].

Moreover, through experiments, numerical simulations, and mechanical methods, scholars have gradually realized that the anchor support cannot only improve the stress state of the surrounding rock (supporting effect) but can also improve the strength index of the anchorage body (reinforcing effect). Therefore, it is considered that the anchor support improves the surrounding rock's mechanical parameters and the surrounding rock cohesion but has little effect on the surrounding rock's internal friction angle [17-19]. At present, an increasing number of researchers have begun to regard the anchor as a reinforcement measure, rather than a separate support structure. The anchor and surrounding rock complex were considered to be an equivalent material with physical and mechanical parameters that were enhanced, and after obtaining the equivalent modulus, Poisson's ratio, cohesion force, and internal friction angle, the analytical solution of the characteristic curve of the surrounding rock of a circular tunnel composite rock under the reinforcement of the anchor was derived [20, 21]. Previously, the Mohr-Coulomb criterion or Hoek-Brown criterion, both of which neglect the intermediate principal stress, were often selected for the analysis of the surrounding rock [22-24]. However, engineering practice has shown that selecting a reasonable strength or yield criterion and considering the dilatancy characteristics of the surrounding rock can more accurately analyze the mechanical state of the surrounding rock. Many scholars have comprehensively considered the intermediate principal stress effect and the dilatancy characteristics of the surrounding rock to establish the elastoplastic analysis model of the surrounding rock and have obtained the analytical solution of the stress and displacement of the anchor support chamber considering the intermediate principal stress and the dilatancy angle [25-28].
The above scholars, through different research ideas, have analyzed the anchorage mechanism of the wholly grouted anchor, established the elastic-plastic analysis model of the surrounding rock of the cavern under the anchor support, and obtained rich research results. However, there are still some shortcomings: (1) most of the calculation models only consider the support effect of the anchor, neglecting the reinforcement effect. (2) When considering the reinforcement effect of the anchor, the mechanical parameters of the equivalent material are obtained by the average distribution of the physical and mechanical parameters of the anchor and the surrounding rock, which ignores the mutual coupling effect between the anchor and the surrounding rock. (3) The intermediate principal stress effect and the dilatancy characteristics of the rock mass are less considered in the model calculation. Therefore, on the basis of previous studies, this paper regards the anchor as a type of reinforcement measure and regards the composite of the anchor and the anchored rock as a bearing structure, which is defined as the surrounding rock reinforcement body. The physical and mechanical parameters of the surrounding rock reinforcement body are obtained under the coupling of the anchor and the anchored rock mass. Considering the intermediate principal stress effect and dilatancy characteristics of the rock mass, the analytical solutions of the stress and the displacement of the surrounding rock reinforcement body and deep surrounding rock are derived. Compared with the FLAC ${ }^{3 \mathrm{D}}$ numerical simulation results and actual monitoring data, the rationality of the method and the reliability of the calculation results are verified.

\section{Surrounding Rock Reinforcement Body and Mechanical Model}

2.1. Define the Surrounding Rock Reinforcement Body. An underground cavern excavation leads to the redistribution of the surrounding rock stress. When the circumferential stress of the cave wall is greater than the compressive strength of the surrounding rock, the surrounding rock begins to plastically yield, and the width of the plastic zone gradually extends from the cave wall to the deep part of the surrounding rock. To increase the integrity and strength of the surrounding rock and to achieve the purpose of supporting surrounding rock, tunnels, chambers, roadways, quarries, and other projects, an anchor is often used as a support form. The traditional surrounding rock loose circle theory states that the anchorage section of an anchor must extend into a certain range of the surrounding rock's elastic zone to play the role of anchor support and ensure the stability of the surrounding rock when the anchor parameters are designed. In the actual project, it is found that the stability of the underground cavern actually depends on the stability of the surrounding rock within the reinforcement range of the anchor.

Therefore, to determine the reasonable anchor support parameters and quantitatively evaluate the stability of the anchored rock mass, the homogenization method is adopted to macroscopically consider the rock mass and anchor complex as a continuous, homogeneous and isotropic surrounding rock reinforcement body. As a new supporting 
structure, the surrounding rock reinforcement body constrains the deformation of the deep surrounding rock.

After cavity excavation, the plastic yield range of surrounding rock extends from the cave wall to the deep section. When the deformation is stable, the plastic zone of surrounding rock is formed with a certain width, as shown in Figure 1(a). When designing the anchor parameters for the cavity, the traditional support theory requires that the loose surrounding rock must be anchored in the stable rock formation, so the anchor length must be greater than the width of the plastic zone, as shown in Figure 1(b). According to the traditional support theory, the surrounding rock reinforcement body shown in Figure 1(d) will be formed. Because the designed length of the anchor is longer, the thickness of the surrounding rock reinforcement body is larger. However, the plastic surrounding rock still has a certain selfstabilizing ability. The anchor does not need to be anchored into the stable rock layer, and only anchors of a certain thickness of surrounding rock are required, as shown in Figure 1(c). Under the new support theory, the surrounding rock reinforcement body shown in Figure 1(e) will be formed.

Under the initial ground stress, a part of the surrounding rock reinforcement body yields plastically. The plastic zone of the surrounding rock reinforcement body is defined as the surrounding rock reinforcement body failure zone, and the elastic zone of the surrounding rock reinforcement body is defined as the surrounding rock reinforcement body stability zone. The physical properties of the surrounding rock reinforcement body are similar to those of the rock, such as the bulk density, specific gravity, porosity, and water absorption. Compared with the physical-mechanical parameters of surrounding rock, the anchor support improves the deformation parameters and the strength parameters of the surrounding rock reinforcement body.

2.2. Establishing a Mechanical Model. Once the anchorage body is equivalent to the surrounding rock reinforcement body, the anchor support form is transformed into the surrounding rock reinforcement body support form, and the surrounding rock reinforcement body is also deformed under the surrounding rock pressure. The mechanical model for reflecting the coordinated deformation between deep surrounding rock and the surrounding rock reinforcement body is established, as shown in Figure 2.

In Figure $2, E_{\mathrm{s}}$ and $\mu_{\mathrm{s}}$ are the elastic modulus and Poisson's ratio of surrounding rock, respectively; $c_{\mathrm{s}}$ and $\varphi_{\mathrm{s}}$ are the cohesion and internal friction angle of surrounding rock, respectively; $E$ and $\mu$ are the elastic modulus and Poisson's ratio of the surrounding rock reinforcement body, respectively; $c$ and $\varphi$ are the cohesion and internal friction angle of the surrounding rock reinforcement body, respectively; $P$ is the initial ground stress; $R_{0}$ is the roadway radius; $L$ is the anchor length; $R_{\mathrm{p}}$ is the radius of the surrounding rock reinforcement body plastic zone; and $R_{1}$ is the radius of the reinforcement body's outer edge, and $R_{1}=R_{0}+$ $L$. The thickness of the reinforcement body is equal to the width of the anchoring zone, which is also equal to the length of the anchor. The following assumptions are made:
(1) For a deep buried cavern, the initial ground stress can be assumed to be equally isotropic $(\lambda=1)$.

(2) There are many discontinuous surfaces of different sizes in the rock mass (except large-scale faults and weak interlayers), but the distribution of these discontinuous surfaces can be approximated as random, and their impact on the rock mass are not very significant as a whole. Therefore, to meet the basic assumptions of the medium in elastoplastic mechanics, the surrounding rock and the surrounding rock reinforcement body are assumed to be continuous, homogeneous, and isotropic elastomers.

(3) The time of the cavern excavation and support is much smaller than the time of the cavern operation, so it can be assumed that the cavern excavation and support are completed instantaneously.

\subsection{Advantages of the Surrounding Rock Reinforcement Body} Support Theory. The principle of modern support is based on the joint bearing of surrounding rock and supporting structure. The composite bearing structure composed of the anchor, and anchored rock mass is analyzed, which can fully exert the self-supporting capacity of surrounding rock. For anchors anchored into the interior of the rock mass, the material properties of the anchor and the rock mass are different so that the deformation (trend) of the two under the same stress field is different. The deformation of the surrounding rock is restrained by the anchor, and the anchor also generates an axial force and deformation due to the deformation of the surrounding rock. Therefore, this paper establishes the theory of the surrounding rock reinforcement body support, which is based on the stability of a composite bearing structure for the anchor support design of surrounding rock. Compared with the traditional support theory, the difference in the surrounding rock reinforcement body support theory lies in the design basis, design method, and support effect evaluation. The details are as follows.

2.3.1. Design Basis. The traditional support theory relies on the plastic zone of the surrounding rock and the radius of the loose rock of the surrounding rock to design the anchor parameters. For soft rock roadways, the radius of the plastic zone is larger, and the required length of the anchor is longer, which increases the construction time and support cost. However, the surrounding rock reinforcement body support theory is based on the stability of the composite which consists of the anchor and the anchored rock mass to design the anchor parameters, which are applicable to any working condition, and can effectively avoid construction difficulties and save support costs.

2.3.2. Design Method. The traditional support theory first designs the length of the anchor and then designs the spacing between the anchors according to engineering experience and the construction scheme. It is not conducive to adjust the spacing between the anchors and the length of the anchor, and the strength of the anchor cannot be fully 


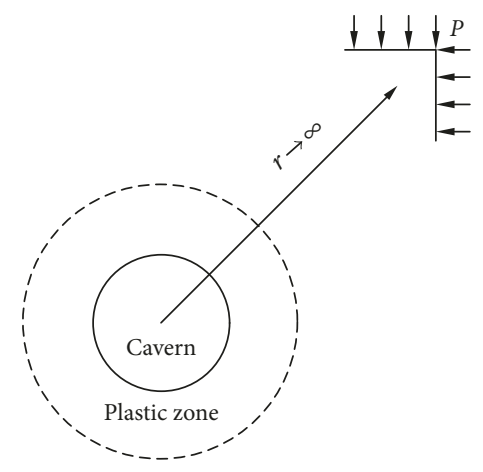

(a)

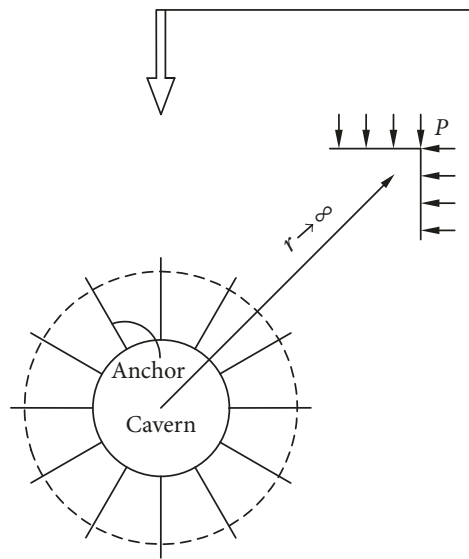

(b)

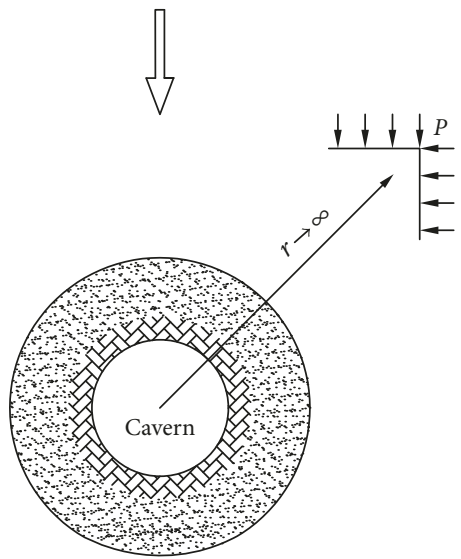

The reinforcement body failure zone

The reinforcement body stability zone

(d)

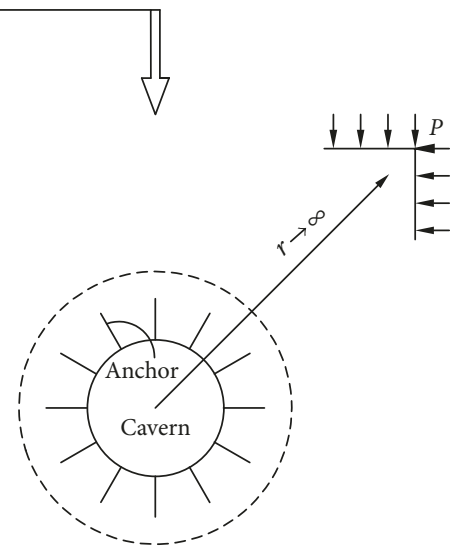

(c)

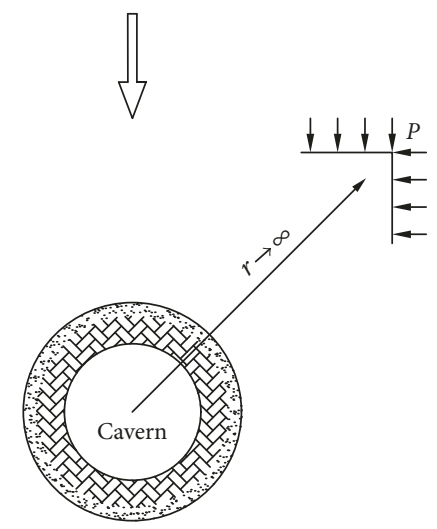

The reinforcement body failure zone

3 The reinforcement body stability zone

(e)

FIGURE 1: Surrounding rock damage evolution and anchor reinforcement: (a) plastic zone width after excavation of the cavern; (b) anchor length is greater than the plastic zone width; (c) anchor length is less than the plastic zone width; $(\mathrm{d}, \mathrm{e})$ the surrounding rock reinforcement body damage zone.

utilized. The surrounding rock reinforcement body support theory can simultaneously consider the anchor length and the spacing between the anchors to design the supporting parameters and repeatedly adjust the anchor parameters to obtain a reasonable supporting strength, which can meet the construction requirements and optimize the support cost.
2.3.3. Support Effect Evaluation. The traditional support theory judges the stability of surrounding rock based on the axial force of the anchor and the deformation of the surrounding rock. The surrounding rock reinforcement body support theory first determines whether the anchor is yielding and then determines the stability of the surrounding rock 


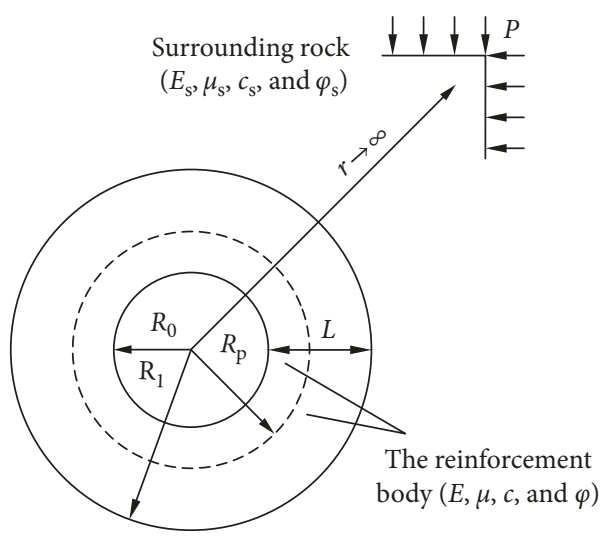

Figure 2: Mechanical model.

according to the degree of deformation of the surrounding rock reinforcement body. The discriminating method is simple and can comprehensively consider the self-stability of the surrounding rock and the anchor support strength.

\section{Derivation of the Physical-Mechanical Parameters of the Surrounding Rock Reinforcement Body}

3.1. The Deformation Parameters of the Surrounding Rock Reinforcement Body. To obtain the deformation parameters of the surrounding rock reinforcement body, first, the support force of the anchor is transformed into the additional volume force of the surrounding rock acting on the interior of the anchored rock mass. Then, the mechanical model of the anchored cavity is established, as shown in Figure 3(a). Finally, an elastic analysis of the surrounding rock is conducted to obtain the radial displacement of the surrounding rock at the two ends of the anchor.

Under the same initial ground stress as the former, the model of the coordinated deformation mechanics of surrounding rock and the surrounding rock reinforcement body is established and analyzed to obtain the radial displacement of the inner and outer edges of the reinforcement body, as shown in Figure 3(b). The equations are established according to the equal deformation of the surrounding rock under the two support forms, and the deformation parameters of the surrounding rock reinforcement body are derived.

3.1.1. Solving the Deformation of Surrounding Rock under the Anchor Support. Studies have shown that the shear stress is 0 in a certain part of the anchor when the anchor and surrounding rock coordinate deform, where the neutral position of the anchor is located. Near the tunnel wall, the surrounding rock has a large deformation and a greater effect on the anchor, and the anchor interface produces an interface shear stress directed towards the center of the tunnel, and the reaction force of the anchor to the surrounding rock points to the distal end of the anchor. Near the distal end of the anchor, the surrounding rock is less deformed and is also affected by the pulling force at the proximal end of the anchor, and the deformation of the surrounding rock is less than the deformation of the anchor. Therefore, the anchor interface generates an interface shear stress directed towards the distal end of the anchor, and the reaction force of the anchor to the surrounding rock points towards the proximal end of the anchor, as shown in Figure 4.

The interfacial shear stress of the anchor is generated by the relative displacement of the anchor and surrounding rock, and the overall displacement of the anchor can be represented by the displacement of surrounding rock at the neutral point. The interfacial shear stress of the wholly grouted anchor can be expressed as

$$
\tau_{\mathrm{b}}(r)=K \Delta u=K\left(u_{\mathrm{r} 2}(\rho)-u_{\mathrm{r} 2}(r)\right),
$$

where $\Delta u$ is the relative displacement of the anchor and surrounding rock, $r$ is the distance from the center of the cavern, $\rho$ is the distance from the neutral point of the anchor to the center of the cavern, $u_{\mathrm{r} 2}(r)$ is the displacement of surrounding rock at $r$, and $u_{\mathrm{r} 2}(\rho)$ is the displacement of surrounding rock at $\rho$. When the anchorage interface is under an elastic lossless condition, $K$ is the comprehensive shear stiffness which considers the grout and rock mass. The physical meaning of $K$ is the shear stress generated by the unit shear displacement on the anchorage of the unit length [30]. This stress can be expressed as

$$
K=\frac{K_{\mathrm{s}} K_{\mathrm{m}}}{K_{\mathrm{s}}+K_{\mathrm{m}}},
$$

where $K_{\mathrm{s}}$ is the shear stiffness of the rock mass, and the appropriate values of which can be selected according to the different rock masses in Table 1 [31]. $K_{\mathrm{m}}$ is the shear stiffness of the grout. Using the results of the literature [32] and then making the appropriate corrections, $K_{\mathrm{m}}$ can be expressed as

$$
K_{\mathrm{m}}=\frac{2 \pi G_{\mathrm{m}}}{\ln \left(1+2 t_{\mathrm{m}} / d_{\mathrm{b}}\right)},
$$

where $G_{\mathrm{m}}$ is the shear modulus of the grout, $t_{\mathrm{m}}$ is the thickness of the grout ring, and $d_{\mathrm{b}}$ is the diameter of the anchor.

The stress analysis of a single anchor is as follows:

$$
\int_{R_{0}}^{R_{0}+L} \tau_{\mathrm{b}}(r) \pi d_{\mathrm{b}} d r=P_{1},
$$

where $P_{1}$ is the pretightening force of the anchor.

The axial force distribution of the anchor is

$$
F(r)=P_{1}-\pi d_{\mathrm{b}} \int_{R_{0}}^{r} \tau_{\mathrm{b}}(r) d r .
$$

The support force of the anchor to surrounding rock is converted into the additional volume force of surrounding rock [14-16], which can be expressed as

$$
f(r)=-\frac{d Q}{d V}=-\frac{\pi d_{\mathrm{b}} R_{0}}{S_{\mathrm{r}} S_{\mathrm{l}}} \cdot \frac{\tau_{\mathrm{b}}(r)}{r},
$$

where $d Q$ is the concentrated force of the unit length of the anchor on the surrounding rock, $d V$ is the volume of surrounding rock within the influence range of the unit length of the anchor, $S_{\mathrm{r}}$ is the circumferential arrangement spacing of the anchor, and $S_{1}$ is the axial arrangement spacing of the anchor. 


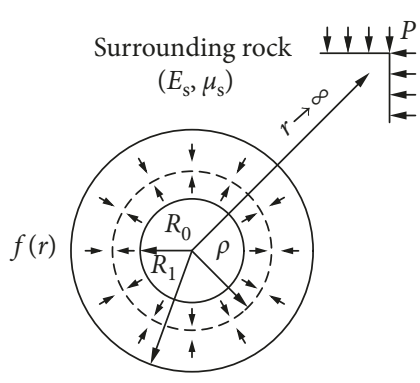

(a)

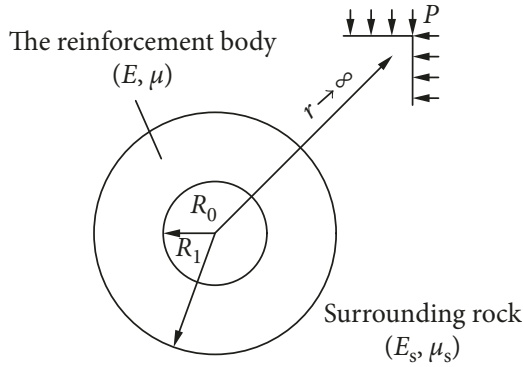

(b)

FIGURE 3: Elastic analysis of the surrounding rock deformation under (a) anchor support and (b) the surrounding rock reinforcement body support.

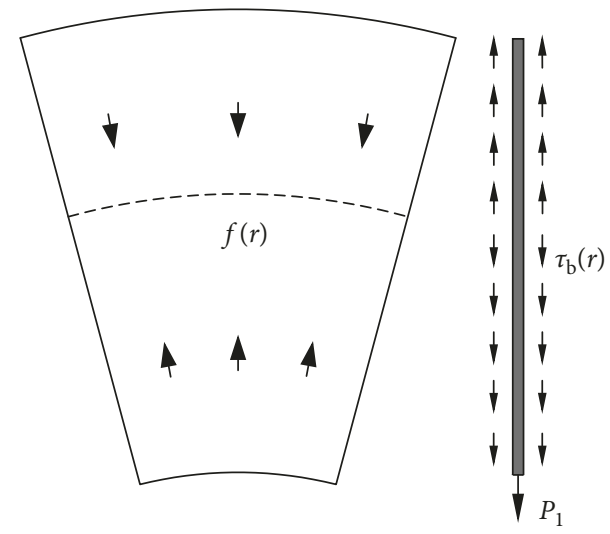

Figure 4: Coordination deformation between the anchor and surrounding rock [29].

TABLE 1: $K_{\mathrm{s}}$ for different rocks [31].

\begin{tabular}{lc}
\hline Rock type & $K_{\mathrm{s}}(\mathrm{GPa})$ \\
\hline Hard rock & $5.00 \sim 10.00$ \\
Soft rock & $1.50 \sim 3.00$ \\
Weathered rock & $1.00 \sim 2.00$ \\
Mudstone & $1.20 \sim 2.50$ \\
Diluvium sand & $0.40 \sim 0.70$ \\
Gravel & $0.40 \sim 0.70$ \\
Diluvium clay & $0.40 \sim 1.00$ \\
Shock layer sand & $0.05 \sim 0.20$ \\
\hline
\end{tabular}

In Figure 3(a), the equilibrium differential equations, geometric equations, and physical equations of surrounding rock are used to obtain the stress and displacement expressions of surrounding rock outside the anchorage body:

$$
\begin{aligned}
& \sigma_{\mathrm{r} 1}=\frac{A_{1}}{r^{2}}+2 C_{1}, \\
& \sigma_{\theta 1}=-\frac{A_{1}}{r^{2}}+2 C_{1}, \\
& u_{\mathrm{r} 1}=\frac{1+\mu_{\mathrm{s}}}{E_{\mathrm{s}}}\left[-\frac{A_{1}}{r}+2\left(1-2 \mu_{\mathrm{s}}\right) C_{1} r\right],
\end{aligned}
$$

where $A_{1}$ and $C_{1}$ are constants.
In Figure 3(a), after the anchor support force is converted into the additional volume force of the surrounding rock, it can be considered that the anchorage body is in equilibrium under the action of the body force $\left(f_{\mathrm{r}}=f(r), f_{\theta}=0\right)$. By establishing equilibrium differential equations, geometric equations, and physical equations in the anchorage body, the stress and displacement expressions of the anchorage body can be solved as follows:

$$
\begin{aligned}
\sigma_{\mathrm{r} 2}= & \frac{A_{2}}{r^{2}}+2 C_{2}-\frac{M(r)}{\left(1-\mu_{\mathrm{s}}\right) r^{2}}-\frac{N(r)}{r^{2}}, \\
\sigma_{\theta 2}= & -\frac{A_{2}}{r^{2}}+2 C_{2}+\frac{M(r)}{\left(1-\mu_{\mathrm{s}}\right) r^{2}}+\frac{N(r)}{r^{2}}-\frac{Q(r)}{1-\mu_{\mathrm{s}}}, \\
u_{\mathrm{r} 2}(r)= & \frac{\left(1+\mu_{\mathrm{s}}\right)}{E_{\mathrm{s}}}\left[-\frac{A_{2}}{r}+2\left(1-2 \mu_{\mathrm{s}}\right) C_{2} r+\frac{M(r)}{\left(1-\mu_{\mathrm{s}}\right) r}\right. \\
& \left.+\frac{N(r)}{r}-r Q(r)\right],
\end{aligned}
$$

where $A_{2}$ and $C_{2}$ are constants, and

$$
\begin{aligned}
& M(r)=\int r\left(\int f(r) d r\right) d r, \\
& N(r)=\int r^{2} f(r) d r, \\
& Q(r)=\int f(r) d r .
\end{aligned}
$$

The boundary conditions are as follows: when $r=R_{0}$, $\sigma_{\mathrm{r} 2}\left(R_{0}\right)=0$; when $r=R_{1}, \quad \sigma_{\mathrm{r} 1}\left(R_{1}\right)=\sigma_{\mathrm{r} 2}\left(R_{1}\right) \quad$ and $u_{\mathrm{r} 1}\left(R_{1}\right)=u_{\mathrm{r} 2}\left(R_{1}\right)$; and when $r \longrightarrow \infty, \sigma_{\mathrm{r} 1}(\infty)=-P$.

Bringing the boundary conditions into equations (7)(9), the constants $A_{1}, C_{1}, A_{2}$, and $C_{2}$ can be solved as follows:

$$
\begin{aligned}
& A_{1}=\frac{2 M-\left(R_{1}^{2}-R_{0}^{2}\right) Q_{1}}{2\left(\mu_{\mathrm{s}}-1\right)}+P R_{0}^{2}-N, \\
& C_{1}=-\frac{1}{2} P, \\
& A_{2}=\frac{Q_{1} R_{0}^{2}-2 M_{0}}{2\left(\mu_{\mathrm{s}}-1\right)}+P R_{0}^{2}+N_{0}, \\
& C_{2}=\frac{2 P\left(1-\mu_{\mathrm{s}}\right)-Q_{1}}{4\left(\mu_{\mathrm{s}}-1\right)},
\end{aligned}
$$


where

$$
\begin{aligned}
M & =\int_{R_{0}}^{R_{1}} r\left(\int f(r) d r\right) d r, \\
M_{0} & =\int_{R_{0}} r\left(\int f(r) d r\right) d r, \\
N & =\int_{R_{0}}^{R_{1}} r^{2} f(r) d r, \\
N_{0} & =\int_{R_{0}} r^{2} f(r) d r, \\
Q_{1} & =\int_{R_{1}} f(r) d r .
\end{aligned}
$$

Bringing the constants $A_{1}, C_{1}, A_{2}$, and $C_{2}$ into equation (8), the radial displacement expression of the anchorage body is obtained as

$$
\begin{aligned}
u_{\mathrm{r} 2}(r)= & \frac{1+\mu_{\mathrm{s}}}{E_{\mathrm{s}}}\left[\frac{2 M_{0}-Q_{1} R_{0}^{2}-2 M(r)}{2\left(\mu_{\mathrm{s}}-1\right) r}\right. \\
& -\frac{\left(1-2 \mu_{\mathrm{s}}\right)\left(2 P \mu_{\mathrm{s}}-2 P+Q_{1}\right) r}{2\left(\mu_{\mathrm{s}}-1\right)} \\
& \left.-\frac{P R_{0}^{2}+N_{0}-N(r)}{r}-r Q(r)\right] .
\end{aligned}
$$

Bringing $r=R_{0}$ and $R_{1}$ into equation (12), the radial displacement of the surrounding rock at the two ends of the anchor can be obtained as follows:

$$
\begin{aligned}
u_{\mathrm{r} 2}\left(R_{0}\right)= & \frac{R_{0}\left(1+\mu_{\mathrm{s}}\right)}{E_{\mathrm{s}}}\left[2 P\left(\mu_{\mathrm{s}}-1\right)+\mathrm{Q}\right], \\
u_{\mathrm{r} 2}\left(R_{1}\right)= & \frac{\left(\mu_{\mathrm{s}}+1\right)}{R_{1}\left(\mu_{\mathrm{s}}-1\right) E_{\mathrm{s}}}\left[\left(1-\mu_{\mathrm{s}}\right) N-\frac{1}{2}\left(R_{1}^{2}-R_{0}^{2}\right) Q_{1}\right. \\
& \left.+M+\left(-2 \mu_{\mathrm{s}}^{2} R_{1}^{2}+R_{1}^{2}+R_{0}^{2}\right) P\right],
\end{aligned}
$$

where $Q=\int_{R_{0}}^{R_{1}} f(r) d r$.
3.1.2. Solving the Deformation of Surrounding Rock under the Reinforcement Body Support. As shown in Figure 3(b), the elastic analysis of the surrounding rock reinforcement body and deep surrounding rock can be used to obtain the stress and displacement expressions, as follows:

$$
\begin{aligned}
& \sigma_{\mathrm{r} j}(r)=\frac{A_{j}}{r^{2}}+2 C_{j}, \\
& \sigma_{\theta j}(r)=-\frac{A_{j}}{r^{2}}+2 C_{j}, \\
& u_{\mathrm{r} j}(r)=\frac{1+\mu_{j}}{E_{j}}\left[-\frac{A_{j}}{r}+2\left(1-2 \mu_{j}\right) C_{j} r\right],
\end{aligned}
$$

where $j=3$ represents surrounding rock outside the surrounding rock reinforcement body, $j=4$ represents the surrounding rock reinforcement body, $E_{3}=E_{\mathrm{s}}, \mu_{3}=\mu_{\mathrm{s}}$, $E_{4}=E$, and $\mu_{4}=\mu$.

The boundary conditions are as follows: when $r=R_{0}$, $\sigma_{\mathrm{r} 4}=0$; when $r=R_{2}, \sigma_{\mathrm{r} 3}=\sigma_{\mathrm{r} 4}$ and $u_{\mathrm{r} 3}=u_{\mathrm{r} 4}$; and when $r \longrightarrow \infty, \sigma_{\mathrm{r} 3}=-P$.

$A_{\mathrm{j}}$ and $C_{\mathrm{j}}$ can be solved by bringing the boundary conditions into equation (14), and the surrounding rock displacement at the two ends of the anchor can be obtained as follows:

$$
\begin{aligned}
& u_{\mathrm{r} 4}\left(R_{0}\right)=\frac{4 P R_{1}^{2} R_{0}\left(\mu^{2}-1\right)\left(\mu_{\mathrm{s}}-1\right)}{\left(2 \mu n_{1}-n_{1}-1\right) E R_{1}^{2}-\left(n_{1}-1\right) E R_{0}^{2}}, \\
& u_{\mathrm{r} 4}\left(R_{1}\right)=\frac{2 P R_{1}(\mu+1)\left(\mu_{\mathrm{s}}-1\right)\left(2 \mu R_{1}^{2}-R_{1}^{2}-R_{0}^{2}\right)}{\left(2 \mu n_{1}-n_{1}-1\right) E R_{1}^{2}-\left(n_{1}-1\right) E R_{0}^{2}},
\end{aligned}
$$

where $n_{1}=E\left(1+\mu_{\mathrm{s}}\right) / E_{\mathrm{s}}(1+\mu)$.

3.1.3. The Expression of the Surrounding Rock Reinforcement Body Deformation Parameter. The equations $u_{\mathrm{r} 2}\left(R_{0}\right)=$ $u_{\mathrm{r} 4}\left(R_{0}\right)$ and $u_{\mathrm{r} 2}\left(R_{1}\right)=u_{\mathrm{r} 4}\left(R_{1}\right)$ can be used to derive the expression of the surrounding rock reinforcement body elastic modulus and Poisson's ratio:

$$
\begin{aligned}
E & =\frac{E_{\mathrm{s}}\left(1+\mu_{\mathrm{s}}\right)^{-1}\left[\left(P \mu_{\mathrm{s}}^{2}-1.5 \mathrm{Q} \mu_{\mathrm{s}}-P+1.5 \mathrm{Q}+Q_{1}\right)\left(R_{1}^{2}-R_{0}^{2}\right)-2\left(\mu_{\mathrm{s}}-1\right)\left(Q R_{0}^{2}-N\right)-2 M\right]}{\left[\left((P-Q)\left(\mu_{\mathrm{s}}-1\right)+0.5 Q_{1}\right)\left(R_{1}^{2}-R_{0}^{2}\right)-\left(\mu_{\mathrm{s}}-1\right)\left(Q R_{0}^{2}-N\right)-M\right]^{2}\left[\left(P \mu_{\mathrm{s}}-P+0.5 Q_{1}\right)\left(R_{1}^{2}-R_{0}^{2}\right)+N\left(\mu_{\mathrm{s}}-1\right)-M\right]^{-1}}, \\
\mu & =\frac{\left[2 P \mu_{\mathrm{s}}^{2}-(2 P+Q) \mu_{\mathrm{s}}+Q+Q_{1}\right]\left(R_{1}^{2}-R_{0}^{2}\right)-2\left(\mu_{\mathrm{s}}-1\right)\left(Q R_{0}^{2}-N\right)-2 M}{\left[2\left(\mu_{\mathrm{s}}-1\right)(P-Q)+Q_{1}\right]\left(R_{1}^{2}-R_{0}^{2}\right)-2\left(\mu_{\mathrm{s}}-1\right)\left(Q R_{0}^{2}-N\right)-2 M} .
\end{aligned}
$$

When the anchor is not supported, $M, N, Q$, and $Q_{1}$ are all equal to $0, E=E_{\mathrm{s}}$, and $\mu=\mu_{\mathrm{s}}$ can be obtained by bringing the coefficients into equation (16).

3.2. The Strength Parameters of the Surrounding Rock Reinforcement Body. The internal friction angle of the surrounding rock reinforcement body is determined by the internal friction angle of the anchor, the internal friction angle of the rock, and the stress state on the friction surface. If the stress states of the anchor and the anchored rock mass are the same, the internal friction angle of the reinforcement body can be obtained according to the area equivalent principle. Because the total area of the anchor in the anchorage area is small, the internal friction angle of the reinforcement body is approximately equal to the internal 
friction angle of the rock mass before being anchored $[17,18]$. The internal friction angle of the reinforcement body can be expressed as

$$
\varphi=\varphi_{\mathrm{s}}
$$

The increase in the cohesion of the surrounding rock reinforcement body is caused by two aspects. One aspect is that the lateral action of the anchor increases the shear strength of the fracture surface, and the other part is that the vertical action of the anchor exerts a certain pressure on surrounding rock, which improves the stress state of the rock mass and increases its nondeformability. The compressive stress applied to the surrounding rock is decomposed into the fracture surface, as shown in Figure 5(a). The shear resistance of the anchor is equally divided on the surrounding rock fracture surface, as shown in Figure 5(b).

Experiments have shown that the maximum principal stress direction of the anchor is perpendicular to the anchor [33], so the angle between the main fracture surface of the anchor and the direction of the maximum principal stress can be expressed as

$$
\beta=\frac{\pi}{4}-\frac{\varphi}{2} .
$$

In Figure 5(b), the cohesion provided by the lateral action of a single anchor can be expressed as

$$
c_{\mathrm{m}}=\frac{R_{0} F_{\mathrm{bmax}}}{r S_{\mathrm{l}} S_{\mathrm{r}} \cos \beta}
$$

where $F_{\mathrm{b} \text { max }}$ is the maximum shear force that the anchor can withstand during pure shearing, and $F_{\mathrm{b} \text { max }}=\sigma_{\mathrm{s}} \pi d_{\mathrm{b}}^{2} / 4 \sqrt{3}$ can be obtained by the Von Mises criterion and $\sigma_{s}$ is the yield strength of the anchor.

In Figure 5(a), the cohesion provided by the vertical action of a single anchor can be expressed as

$$
c_{\mathrm{n}}=\frac{R_{0} F(r)}{r S_{1} S_{\mathrm{r}}} \cos \beta \tan \varphi .
$$

The cohesion of the surrounding rock reinforcement body at $r$ is expressed as

$$
c(r)=c_{\mathrm{s}}+c_{\mathrm{m}}+c_{\mathrm{n}} .
$$

Some scholars have proposed a homogenization method which means that the surrounding rock is regarded as a homogeneous elastomer, and the physicomechanical parameters that vary from place to place are converted into equal parameters. By the homogenization method, the cohesion of the surrounding rock reinforcement body can be expressed as

$$
\begin{aligned}
c & =\frac{1}{L} \int_{R_{0}}^{R_{0}+L} c(r) d r \\
& =c_{\mathrm{s}}+\frac{\sigma_{\mathrm{s}} \pi d_{\mathrm{b}}^{2} R_{0} \ln \left(1+\left(L / R_{0}\right)\right)}{4 \sqrt{3} L S_{\mathrm{r}} S_{1} \cos \beta}+\frac{R_{0} \int_{R_{0}}^{R_{0}+L}(F(r) / r) d r}{\sec \beta \cot \varphi L S_{\mathrm{r}} S_{1}} .
\end{aligned}
$$

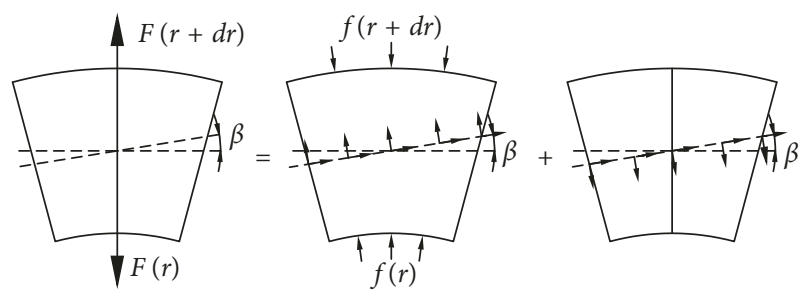

FIGURE 5: Influence of the anchor on the cohesive force of the surrounding rock reinforcement body: (a) the wedge-shaped unit of the anchor and surrounding rock; (b) anchor vertical action; (c) anchor lateral action.

When the anchor is not supported, the anchor length $L$ and the anchor axial force $F(r)$ are equal to 0 , and $c=c_{\mathrm{s}}$ can be obtained by bringing $L$ and $F(r)$ into equation (22).

\section{Elastoplastic Solution of the Mechanical Model and Stability Evaluation of Surrounding Rock}

4.1. Analysis of the Plastic Zone. To consider the influence of the intermediate principal stress $\sigma_{2}$, the unified strength theory is used in this paper. In the reinforcement body, the unified strength theory is expressed as follows [27]:

$$
\sigma_{\theta}^{\mathrm{p}}-m \sigma_{\mathrm{r}}^{\mathrm{p}}-n=0,
$$

where

$$
\begin{aligned}
& m=\frac{(1+\sin \varphi)(1+\mu b)}{(1-\sin \varphi)(1+b)-(1+\sin \varphi) \mu b}, \\
& n=\frac{2 c \cos \varphi(1+b)}{(1-\sin \varphi)(1+b)-(1+\sin \varphi) \mu b},
\end{aligned}
$$

where $b$ is the intermediate principal stress coefficient.

The equilibrium differential equation of surrounding rock in the plastic zone of the reinforcement body can be expressed as

$$
\frac{d \sigma_{\mathrm{r}}^{\mathrm{p}}}{d r}+\frac{\sigma_{\mathrm{r}}^{\mathrm{p}}-\sigma_{\theta}^{\mathrm{p}}}{r}=0
$$

Through the simultaneous equations (23)-(25) and the boundary condition $\sigma_{\mathrm{rp}}\left(R_{0}\right)=0$, the stress distribution of the reinforcement body plastic zone can be solved as follows:

$$
\begin{aligned}
\sigma_{\mathrm{r}}^{\mathrm{p}}(r) & =\frac{-n+n r^{m-1} R_{0}^{1-m}}{m-1}, \\
\sigma_{\theta}^{\mathrm{p}}(r) & =\frac{-n+m n r^{m-1} R_{0}^{1-m}}{m-1} .
\end{aligned}
$$

4.2. Analysis of the Elastic Zones. It is known from elastic mechanics that the stress and the displacement expressions of surrounding rock of the elastic zones I and II can be expressed as 


$$
\begin{aligned}
& \sigma_{\mathrm{ri}}^{\mathrm{e}}(r)=-\frac{A_{i}}{r^{2}}-2 C_{i}, \\
& \sigma_{\theta i}^{\mathrm{e}}(r)=\frac{A_{i}}{r^{2}}-2 C_{i}, \\
& u_{\mathrm{r} i}^{\mathrm{e}}(r)=\frac{1+\mu_{i}}{E_{i}}\left[\frac{A_{i}}{r}-2\left(1-2 \mu_{i}\right) C_{i} r\right],
\end{aligned}
$$

where $i=$ I represents surrounding rock of the elastic zone I, $i=$ II represents surrounding rock of the elastic zone II, and $E_{\mathrm{I}}=E, \mu_{\mathrm{I}}=\mu, E_{\mathrm{II}}=E_{\mathrm{s}}$, and $\mu_{\mathrm{II}}=\mu_{\mathrm{s}}$.

The boundary conditions are as follows: when $r \longrightarrow \infty$, $\sigma_{\text {rII }}^{\mathrm{e}}(\infty)=P$; $\quad$ when $r=R_{1}, \quad \sigma_{\text {rII }}^{\mathrm{e}}\left(R_{1}\right)=\sigma_{\text {rI }}^{\mathrm{e}}\left(R_{1}\right) \quad$ and $u_{\mathrm{rII}}^{\mathrm{e}}\left(R_{1}\right)=u_{\mathrm{rI}}^{\mathrm{e}}\left(R_{1}\right)$; and when $r=R_{\mathrm{p}}, \sigma_{\mathrm{rI}}^{\mathrm{e}}\left(R_{\mathrm{p}}\right)=\sigma_{\mathrm{r}}^{\mathrm{p}}\left(R_{\mathrm{p}}\right)=p$.

By bringing the boundary conditions into equations (26) and (27), $A_{\mathrm{I}}, C_{\mathrm{I}}, A_{\mathrm{II}}$, and $C_{\mathrm{II}}$ can be solved as follows:

$$
\begin{aligned}
A_{\mathrm{I}} & =\frac{R_{\mathrm{p}}^{2} R_{1}^{2}\left(-2 n_{2} p \mu+2 P \mu_{\mathrm{s}}+n_{2} p-2 P+p\right)}{\left(2 \mu n_{2}-n_{2}-1\right) R_{1}^{2}-\left(n_{2}-1\right) R_{\mathrm{p}}^{2}}, \\
A_{\mathrm{II}} & =\frac{P R_{1}^{4}\left(2 \mu n_{2}-n_{2}-2 \mu_{\mathrm{s}}+1\right)-R_{\mathrm{p}}^{2} R_{1}^{2} \cdot\left(2 n_{2} p \mu+n_{2} P-2 n_{2} p+P-2 P \mu_{\mathrm{s}}\right)}{\left(2 \mu n_{2}-n_{2}-1\right) R_{1}^{2}-\left(n_{2}-1\right) R_{\mathrm{p}}^{2}}, \\
C_{\mathrm{I}} & =\frac{-2 P R_{1}^{2}\left(\mu_{\mathrm{s}}-1\right)+p R_{\mathrm{p}}^{2}\left(n_{2}-1\right)}{2\left(2 \mu n_{2}-n_{2}-1\right) R_{1}^{2}-2\left(n_{2}-1\right) R_{\mathrm{p}}^{2}} \\
C_{\mathrm{II}} & =-\frac{1}{2} P
\end{aligned}
$$

where

$$
\begin{aligned}
n_{2} & =\frac{E_{\mathrm{s}}(1+\mu)}{E\left(1+\mu_{\mathrm{s}}\right)}, \\
p & =\frac{-n+n R_{\mathrm{p}}^{m-1} R_{0}^{1-m}}{m-1} .
\end{aligned}
$$

At the elastoplastic interface, the radial stress $\sigma_{\mathrm{rI}}^{\mathrm{e}}\left(R_{\mathrm{p}}\right)$ and the circumferential stress $\sigma_{\theta \mathrm{I}}^{\mathrm{e}}\left(R_{\mathrm{p}}\right)$ of the surrounding rock reinforcement body's elastic zone satisfy the yield condition:

$$
\sigma_{\theta \mathrm{I}}^{\mathrm{e}}\left(R_{\mathrm{p}}\right)-m \sigma_{\mathrm{rI}}^{\mathrm{e}}\left(R_{\mathrm{p}}\right)-n=0 .
$$

$\sigma_{\mathrm{rI}}^{\mathrm{e}}\left(R_{\mathrm{p}}\right)$ and $\sigma_{\theta \mathrm{I}}^{\mathrm{e}}\left(R_{\mathrm{p}}\right)$ can be obtained by bringing $A_{\mathrm{I}}, C_{\mathrm{I}}$, $A_{\mathrm{II}}$, and $C_{\mathrm{II}}$ into equation (27), and the relationship between $R_{\mathrm{p}}$, surrounding rock parameters, and the anchor parameters can be derived by bringing $\sigma_{\mathrm{rI}}^{\mathrm{e}}\left(R_{\mathrm{p}}\right)$ and $\sigma_{\theta \mathrm{I}}^{\mathrm{e}}\left(R_{\mathrm{p}}\right)$ into equation (30):

$$
\begin{aligned}
& \frac{\left(R_{\mathrm{p}}^{m-1} R_{0}^{1-m}-1\right)}{n^{-1}\left(1-m^{-1}\right)}-\left[\left(-2 \mu n_{2}+n_{2}+1\right) R_{1}^{2}-\left(n_{2}-1\right) R_{\mathrm{p}}^{2}\right] \\
& \quad \frac{\left(-n+n R_{\mathrm{p}}^{m-1} R_{0}^{1-m}\right)+4 P R_{1}^{2}\left(\mu_{\mathrm{s}}-1\right)(m-1)}{(m-1)\left[\left(2 \mu n_{2}-n_{2}-1\right) R_{1}^{2}-\left(n_{2}-1\right) R_{\mathrm{p}}^{2}\right]}+n=0 .
\end{aligned}
$$

When $b=0$ and the anchor is not supported, equation (31) can be degenerated into an expression of the modified Fenner formula:

$$
R_{\mathrm{p}}=R_{0}\left[\frac{\left(P+c_{\mathrm{s}} \cot \phi_{\mathrm{s}}\right)\left(1-\sin \phi_{\mathrm{s}}\right)}{c_{\mathrm{s}} \cot \phi_{\mathrm{s}}}\right]^{\left(1-\sin \phi_{\mathrm{s}}\right) /\left(2-\sin \phi_{\mathrm{s}}\right)} .
$$

4.3. Solving the Displacement of the Plastic Zone. The rock mass material has dilatancy characteristics, the volumetric strain of the plastic zone is not equal to 0 , and the plastic zone satisfies the following nonassociated flow rules [28]:

$$
\beta \varepsilon_{\theta}^{\mathrm{pp}}+\varepsilon_{\mathrm{r}}^{\mathrm{pp}}=0
$$

where $\beta$ is the dilatancy coefficient, and $\beta=((1+\sin \psi) /$ $(1-\sin \psi))$, where $\psi$ is the dilatancy angle of surrounding rock in the plastic zone. Generally, the dilatancy angle of surrounding rock is less than or equal to the internal friction angle of surrounding rock.

The total strain of the plastic zone can be regarded as the superposition of the elastic strain and the plastic strain of the plastic zone:

$$
\begin{aligned}
\varepsilon_{\theta}^{\mathrm{p}} & =\varepsilon_{\theta}^{\mathrm{pp}}+\varepsilon_{\theta}^{\mathrm{pe}}, \\
\varepsilon_{\mathrm{r}}^{\mathrm{p}} & =\varepsilon_{\mathrm{r}}^{\mathrm{pp}}+\varepsilon_{\mathrm{r}}^{\mathrm{pe}} .
\end{aligned}
$$

By bringing the geometric equations $\varepsilon_{\mathrm{r}}=d u / d r$ and $\varepsilon_{\theta}=$ $u / r$ into equations (33) and (34), the differential equation of the plastic zone displacement can be derived as

$$
\frac{d u^{\mathrm{p}}(r)}{d r}+\beta \frac{u^{\mathrm{p}}(r)}{r}=\beta \varepsilon_{\theta}^{\mathrm{p}}+\varepsilon_{\mathrm{r}}^{\mathrm{p}}=\beta \varepsilon_{\theta}^{\mathrm{pe}}+\varepsilon_{\mathrm{r}}^{\mathrm{pe}} .
$$

The paper deals with the plane strain problem, so the elastic strain in the plastic zone still satisfies the generalized Hooke's law:

$$
\begin{gathered}
\varepsilon_{\theta}^{\mathrm{pe}}=\frac{1-\mu^{2}}{E}\left(\sigma_{\theta}^{\mathrm{p}}-\frac{\mu}{1-\mu} \sigma_{\mathrm{r}}^{\mathrm{p}}\right), \\
\varepsilon_{\mathrm{r}}^{\mathrm{pe}}=\frac{1-\mu^{2}}{E}\left(\sigma_{\mathrm{r}}^{\mathrm{p}}-\frac{\mu}{1-\mu} \sigma_{\theta}^{\mathrm{p}}\right) .
\end{gathered}
$$


By bringing the boundary condition $u^{\mathrm{p}}\left(R_{\mathrm{p}}\right)=u_{\mathrm{r} 1}^{e}\left(R_{\mathrm{p}}\right)=$ $Z$ into equations (35) and (36), the displacement expression of the plastic zone can be solved as

$$
u^{\mathrm{p}}(r)=\left(X R_{\mathrm{p}}^{\beta+m}-Y R_{\mathrm{p}}^{\beta+1}+Z R_{\mathrm{p}}^{\beta}\right) r^{-\beta}-X r^{m}+Y r,
$$

where

$$
\begin{aligned}
& X=\frac{n[(\beta+1)(m+1) \mu-\beta m-1]}{(\mu+1)^{-1} E(m-1)(\beta+m) R_{0}^{m-1}}, \\
& Y=\frac{n(\mu+1)(2 \mu-1)}{E(m-1)} .
\end{aligned}
$$

4.4. Evaluation Method of the Surrounding Rock Stability. First, it is necessary to ensure that the displacement of the cave wall is not greater than the maximum displacement allowed in the cave wall and that it does not affect the normal use of the cavity. Second, it must be ensured that the anchor does not yield and that the maximum shear stress of the anchor does not exceed the shear strength of the anchoring agent. If the anchor yield or the maximum shear stress of the anchor is greater than that of the shear strength of the anchoring agent, the bearing structure of the surrounding rock reinforcement body cannot be formed. Finally, it must be ensured that the bearing structure of the surrounding rock reinforcement body does not fully yield. Even if a part of the surrounding rock reinforcement body has yielded, it can constrain the surrounding rock deformation and controls the surrounding rock stability.

\subsubsection{Displacement of the Cave Wall.}

$$
u_{0}=u^{\mathrm{p}}\left(R_{0}\right) \leq[u]
$$

where $[u]$ is the maximum displacement allowed in the cave wall.

4.4.2. Maximum Axial Force $F_{\max }$ and Maximum Shear Stress of Anchor $\tau_{\text {bmax }}$

(1) If $\rho>R_{\mathrm{p}}$

$$
\begin{aligned}
\tau_{\mathrm{bmax}}= & K\left(u^{\mathrm{p}}\left(R_{0}\right)-u_{\mathrm{r} 1}^{\mathrm{e}}(\rho)\right), \\
F_{\max }= & \int_{R_{0}}^{R_{\mathrm{p}}} K\left(u^{\mathrm{p}}(r)-u_{\mathrm{r} 1}^{\mathrm{e}}(\rho)\right) d r \\
& +\int_{R_{\mathrm{p}}}^{\rho} K\left(u_{\mathrm{r} 1}^{\mathrm{e}}(r)-u_{\mathrm{r} 1}^{\mathrm{e}}(\rho)\right) d r .
\end{aligned}
$$

(2) If $\rho<R_{\mathrm{p}}$

$$
\begin{aligned}
\tau_{\mathrm{bmax}} & =K\left(u^{\mathrm{p}}\left(R_{0}\right)-u^{\mathrm{p}}(\rho)\right), \\
F_{\text {max }} & =\int_{R_{0}}^{R_{\mathrm{p}}} K\left(u^{\mathrm{p}}(r)-u^{\mathrm{p}}(\rho)\right) d r .
\end{aligned}
$$

For the above two cases, it must be guaranteed:

$$
\begin{aligned}
\tau_{\mathrm{b} \max } & \leq\left[\tau_{\mathrm{m}}\right], \\
F_{\max } & \leq[F],
\end{aligned}
$$

where $\left[\tau_{\mathrm{m}}\right]$ is the maximum shear stress allowed in the anchoring agent and $[F]$ is the maximum tensile force allowed in the anchor.

4.4.3. Define the Stability Coefficient of Surrounding Rock. When the initial ground stress is small or the anchor support strength is high, the surrounding rock reinforcement body is in an entirely elastic state, which indicates that surrounding rock has good stability. When the initial ground stress is large or the anchor support strength is very low, the surrounding rock reinforcement body is in an entirely plastic state, which indicates that the surrounding rock stability is poor, and the surrounding rock is about to become or has become unstable. Under a certain initial ground stress, reasonable anchor support parameters will cause the surrounding rock reinforcement body to partially yield, but it still can constrain the deformation of surrounding rock and better control the stability of surrounding rock. Therefore, the surrounding rock stability coefficient $k$ is defined, which indicates the proportion of the surrounding rock reinforcement body stability zone in the entire reinforcement body under the initial geostress $P$. The surrounding rock stability coefficient $k$ can be expressed as

$$
k=1-\frac{R_{\mathrm{p}}-R_{0}}{L}
$$

(1) When $k=0$, it means that the surrounding rock reinforcement body is in an entirely plastic state, and the surrounding rock stability is very poor

(2) When $0<k<1$, it means that a part of the surrounding rock reinforcement body is in a plastic state, and the larger the $k$ is, the better the surrounding rock stability is

(3) When $k=1$, it means that the surrounding rock reinforcement body is in an entirely elastic state, and the surrounding rock stability is excellent

\section{Engineering Case Analysis}

The radius of a circular cavern excavation is $R_{0}=3 \mathrm{~m}$, the depth of the cavern is $400 \mathrm{~m}$, and the bulk density of the overburden is $20 \mathrm{kN} / \mathrm{m}$. The initial ground stress is $P_{0}=$ $8 \mathrm{MPa}$, and the surrounding rock grade is grade IV. The mechanical properties of the rock mass are as follows: elastic modulus $E_{\mathrm{s}}=1.5 \mathrm{GPa}$; Poisson's ratio $\mu_{\mathrm{s}}=0.3$; cohesion $c_{\mathrm{s}}=$ $1 \mathrm{MPa}$; and internal friction angle $\varphi_{\mathrm{s}}=30^{\circ}$. The anchor support parameters of the cavern are shown in Table 2.

5.1. Verification of the Theory and an Analytical Solution. Based on the example of the appeal project, the analytical solution is obtained by using the theory of this paper, and the FLAC $^{3 \mathrm{D}}$ finite difference program is used for numerical 
TABLE 2: Anchor support parameters.

\begin{tabular}{lc}
\hline Parameter & Value \\
\hline$E_{\mathrm{b}}(\mathrm{GPa})$ & 210 \\
$P_{1}(\mathrm{kN})$ & 0 \\
$d_{\mathrm{b}}(\mathrm{mm})$ & 20 \\
$t_{\mathrm{m}}(\mathrm{mm})$ & 10 \\
$L(\mathrm{~m})$ & 2.4 \\
$S_{\mathrm{r}}(\mathrm{m})$ & 1.0 \\
$S_{\mathrm{l}}(\mathrm{m})$ & 1.0 \\
$\sigma_{\mathrm{s}}(\mathrm{MPa})$ & 335 \\
\hline
\end{tabular}

simulation. The analytical solution is compared with the numerical solution, and then the above are compared with the actual monitoring data to verify the rationality of the deduced analytical formula.

The physical-mechanical parameters of the surrounding rock reinforcement body are calculated by bringing the surrounding rock parameters and anchor parameters into equations (1)-(22), as shown in Table 3. The calculation process is as follows.

Bringing the surrounding rock parameters and anchor parameters into equations (1)-(12) can solve the shear stress expression of the anchor interface and the axial force expression of the anchor:

$$
\begin{aligned}
\tau_{\mathrm{b}}(r) & =1.507 \times 10^{4}-\frac{6.152 \times 10^{4}}{r}, \\
F(r) & =3.865 \times 10^{3} \times \ln \left(\frac{r}{3}\right)-0.947 \times 10^{3} \times r+2.840 \times 10^{3} .
\end{aligned}
$$

It can be known from equation (6) that the additional volume force of the surrounding rock can be derived from the shear stress of the anchor interface:

$$
f(r)=\frac{1.160 \times 10^{4}-0.284 \times 10^{4} \times r}{r^{2}} .
$$

$M(r), N(r)$, and $Q(r)$ can be calculated from $f(r)$, and the integral coefficients $M, N, Q$, and $Q_{1}$ can be solved as follows:

$$
\begin{aligned}
M & =-6.930 \times 10^{4}, \\
N & =-0.797 \times 10^{3}, \\
Q & =48.617, \\
Q_{1} & =-6.937 \times 10^{3} .
\end{aligned}
$$

Bringing the integral constant obtained above into equation (16) can solve the deformation parameters of the surrounding rock reinforcement body:

$$
\begin{aligned}
E & =1.510 \mathrm{GPa}, \\
\mu & =0.297 .
\end{aligned}
$$

It can be seen from equation (17) that the friction angle of the surrounding rock reinforcement body is

$$
\varphi=30^{\circ} \text {. }
$$

TABLE 3: Physical-mechanical parameters of the surrounding rock reinforcement body.

\begin{tabular}{lc}
\hline Parameter & Value \\
\hline$E(\mathrm{GPa})$ & 1.510 \\
$\mu$ & 0.297 \\
$c(\mathrm{MPa})$ & 1.077 \\
$\varphi\left({ }^{\circ}\right)$ & 30 \\
\hline
\end{tabular}

It is known from equations (18)-(22) that the cohesive force of the surrounding rock reinforcement body can be derived from the anchor parameters and the anchor's axial force:

$$
c=1.077 \mathrm{MPa}
$$

It can be seen from Table 3 that, compared with the physical-mechanical parameters of surrounding rock, the elastic modulus and cohesion of the surrounding rock reinforcement body are increased by $0.67 \%$ and $7.70 \%$, respectively, the Poisson's ratio of the surrounding rock reinforcement body is decreased by $1.00 \%$, and the anchor support had the greatest influence on the cohesion of the surrounding rock reinforcement body. The following parameters can be solved by bringing the physical-mechanical parameters of the surrounding rock reinforcement body in Table 3 into equations (23)-(38): the radius of the surrounding rock reinforcement body failure zone is $R_{\mathrm{p}}=$ $4.88 \mathrm{~m}$; the displacement of the cave wall is $u_{0}=47.40 \mathrm{~mm}$; the maximum axial force of the anchor is $F_{\max }=100.54 \mathrm{kN}<$ $[F]=200 \mathrm{kN}$; the maximum shear stress of the anchor is $\tau_{\text {bmax }}=5.44 \mathrm{MPa}<[\tau]=10 \mathrm{MPa}$; and the stability coefficient of surrounding rock is $k=0.216$. Furthermore, the expressions of stress and the displacement of the surrounding rock reinforcement body and deep surrounding rock can be solved.

The influence of the cavern excavation on surrounding rock is $3 \sim 5$ times the width or height of the cavern excavation, so the size of the model is $60 \mathrm{~m} \times 60 \mathrm{~m} \times 1 \mathrm{~m}$. Due to the model's axis symmetry, only a quarter of the mesh model is selected for calculations. The left boundary of the model is constrained by the displacement of the $X$-axis direction, the lower boundary is constrained by the displacement of the $Y$-axis direction, and the displacement of the normal direction is set to 0 based on the plane assumption. When analyzing the surrounding rock, the elastoplastic constitutive model, the unified strength theory, and the unrelated flow rule are used. The supporting materials are all linearly elastic materials, and the grout parameters are set at the same values as the rock parameters. Since the cavity is buried deep, the initial geostress can be considered to be equal in all directions, and the horizontal direction and the vertical direction of the applied boundary stress are both $8 \mathrm{MPa}$. The model consists of 846 zones, which contain 1826 grid points. The numerical calculation model is shown in Figure 6.

Figure 7 is a comparison of the results of the theoretical solution and the numerical simulation. It can be seen that the radius of the surrounding rock reinforcement body 


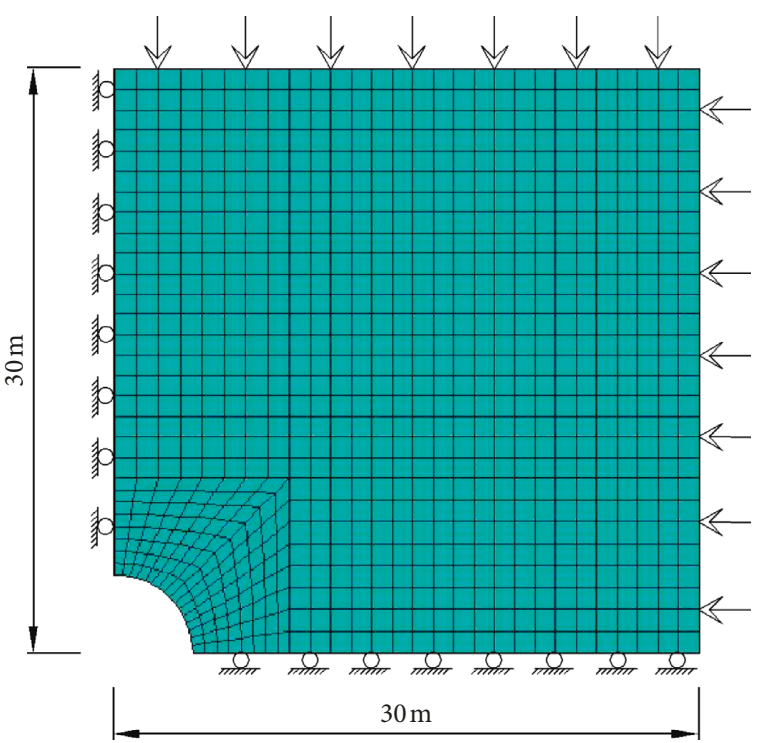

(a)

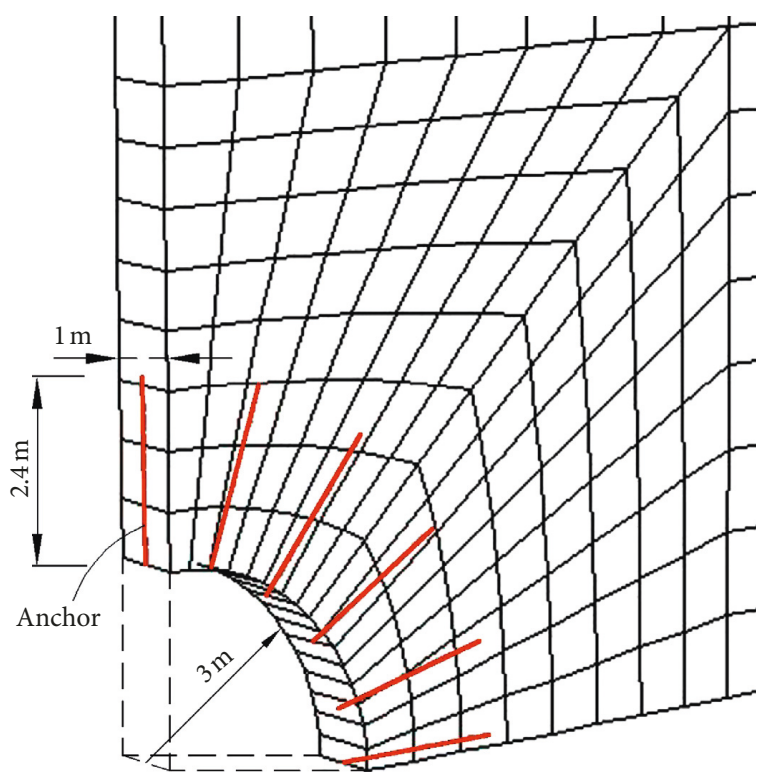

(b)

FIGURE 6: Numerical calculation model: (a) model size and boundary conditions; (b) anchor arrangement.

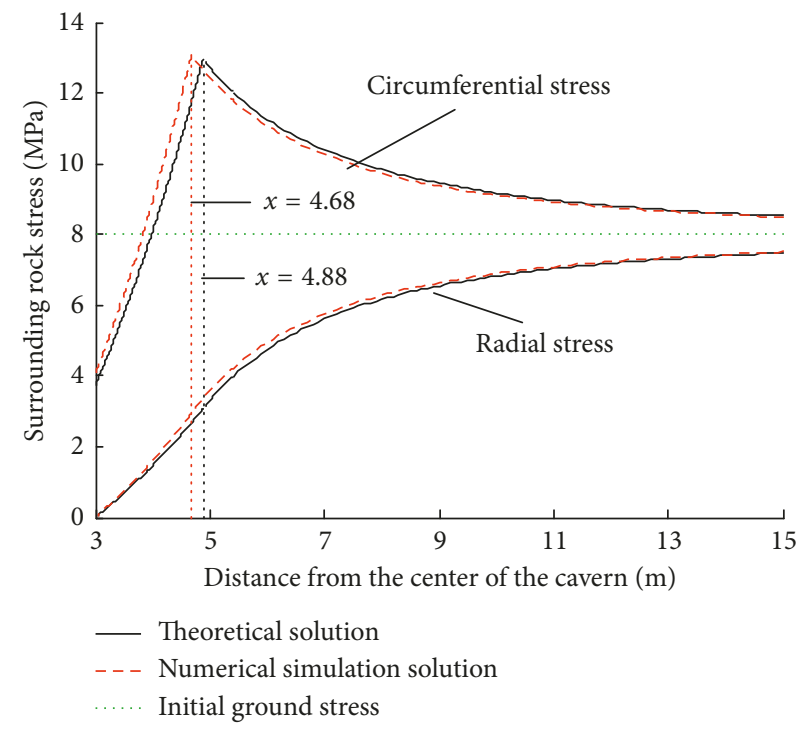

(a)

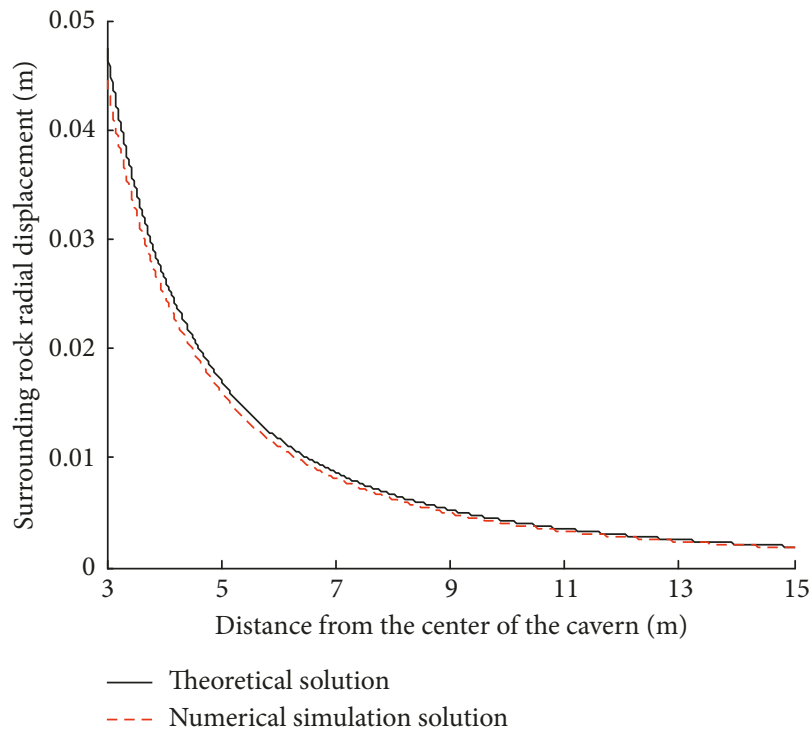

(b)

FIGURE 7: Comparison of the theoretical solution and numerical simulation results: (a) stress comparison; (b) displacement comparison.

damage zone solved by the theory is $4.88 \mathrm{~m}$, and the radius of the surrounding rock plastic zone obtained via numerical simulation is $4.68 \mathrm{~m}$. At the cave wall, the circumferential and lateral stresses of the surrounding rock obtained by the theory are $3.73 \mathrm{MPa}$ and $47.39 \mathrm{~mm}$, respectively, and the circumferential and lateral displacements of the surrounding rock obtained by numerical simulation are $4.06 \mathrm{MPa}$ and $44.61 \mathrm{~mm}$, respectively. The greater the distance from the center of the cave, the smaller the difference between the theoretical solution and the numerical solution. In general, the theoretical analytical solution agrees well with the numerical simulation results.
In the actual project, the initial design of the anchor spacing is $1.0 \times 1.0 \mathrm{~m}$. After actual monitoring, it is determined that the maximum axial force of the anchor is far from the ultimate tensile strength, and the anchor strength is not fully exerted. Therefore, the anchor spacing is adjusted to $1.2 \times 1.2 \mathrm{~m}$, and a pretightening force of $100 \mathrm{kN}$ is applied to the anchor. The displacement of the tunnel wall and the axial forces of the anchor under the new support scheme are monitored. To further verify the rationality of the theory, the theoretical solutions under the two support schemes are compared with the actual monitoring data and numerical simulation results, as shown in Table 4 . 
TABle 4: Comparison of results.

\begin{tabular}{|c|c|c|c|c|c|c|c|c|c|}
\hline & \multirow{2}{*}{$\begin{array}{l}\text { Anchor } \\
\text { length } \\
(\mathrm{m})\end{array}$} & \multirow{2}{*}{$\begin{array}{l}\text { Anchor } \\
\text { spacing } \\
(\mathrm{m})\end{array}$} & \multicolumn{3}{|c|}{ The displacement of the tunnel wall (mm) } & \multicolumn{3}{|c|}{ The axial force of the anchor $(\mathrm{kN})$} & \multirow[b]{2}{*}{$k$} \\
\hline & & & $\begin{array}{l}\text { Theoretical } \\
\text { value }\end{array}$ & $\begin{array}{l}\text { Numerical } \\
\text { solution }\end{array}$ & $\begin{array}{c}\text { Monitoring } \\
\text { value }\end{array}$ & $\begin{array}{c}\text { Theoretical } \\
\text { value }\end{array}$ & $\begin{array}{l}\text { Numerical } \\
\text { solution }\end{array}$ & $\begin{array}{l}\text { Monitoring } \\
\text { value }\end{array}$ & \\
\hline Scheme 1 & 2.4 & $1.0 \times 1.0$ & 47.40 & 44.61 & 43.78 & 100.54 & 107.21 & 97.32 & 0.216 \\
\hline Scheme 2 & 2.4 & $1.2 \times 1.2$ & 47.36 & 44.52 & 43.14 & 190.48 & 192.14 & 186.23 & 0.218 \\
\hline
\end{tabular}

It can be seen from Table 4 that, under the support of schemes 1 and 2, the theoretical calculations agree well with the numerical simulation results, and the differences between the theoretical value, the numerical solution, and the actual monitored value are less than $10 \%$, which verifies the rationality of the surrounding rock reinforcement body theory and illustrates the accuracy of the method. It can also be seen that, under the new support scheme, not only is the stability of the surrounding rock ensured but also the strength of the anchor is also fully utilized, the amount of the anchor is saved, and the anchor support parameters can be optimized.

\subsection{Analysis of Influencing Parameters}

5.2.1. Influence of the Anchor Support Parameters on the Stability Coefficient of the Surrounding Rock. Figure 8 is a graph showing the effect of the combination of the anchor length and spacing on the stability coefficient of the surrounding rock. It can be seen that the value of $k$ increases as the length of the anchor increases or the spacing of the anchor decreases. However, when the anchor length is longer or the anchor spacing is larger, the curve of $k$ becomes more gradual. Since the anchor belongs to a point support, to eliminate the occurrence of the collapse of surrounding rock between the anchors, the anchor length is taken as $L \geq 2 S_{\mathrm{r}}, 2 S_{1}$. When the anchor spacing is $0.8 \times 0.8 \mathrm{~m}$, the value of $k$ increases by 0.61 as the length of the anchor increases from $1.6 \mathrm{~m}$ to $4.4 \mathrm{~m}$, and the value of $k$ is equal to 0 when the anchor length is less than or equal to $1.8 \mathrm{~m}$, which means that all of the surrounding rock reinforcement body yields. When the anchor spacing is $1.0 \times 1.0 \mathrm{~m}$, the value of $k$ increases by 0.54 as the anchor length increases from $2 \mathrm{~m}$ to $4.4 \mathrm{~m}$. When the anchor spacing is $1.2 \times 1.2 \mathrm{~m}$, the value of $k$ increases by 0.37 as the anchor length increases from $2.4 \mathrm{~m}$ to $4.4 \mathrm{~m}$. When the anchor length is equal to $2.4 \mathrm{~m}$, the value of $k$ decreases by $19.91 \%$ with the anchor spacing from $0.8 \times 0.8 \mathrm{~m}$ to $1.2 \times 1.2 \mathrm{~m}$, and when the anchor length is larger, the anchor spacing has a smaller effect on the surrounding rock stability coefficient. In general, the influence of the anchor length and spacing on the stability of surrounding rock is greater.

Figure 9 is a graph showing the influence of the anchor pretightening force and the anchor diameter on the surrounding rock stability coefficient. It can be seen that the value of $k$ increases linearly as the anchor pretightening force and the anchor diameter increase. When the anchor diameter is equal to $20 \mathrm{~mm}$, the value of $k$ increases by $12.65 \%$ as the anchor pretightening force increases from 0 to $100 \mathrm{kN}$. When the anchor pretightening force is not taken into account, the value of $k$ increases by $8.24 \%$ with an increase in the anchor diameter from $18 \mathrm{~mm}$ to $22 \mathrm{~mm}$. It can also be seen that the

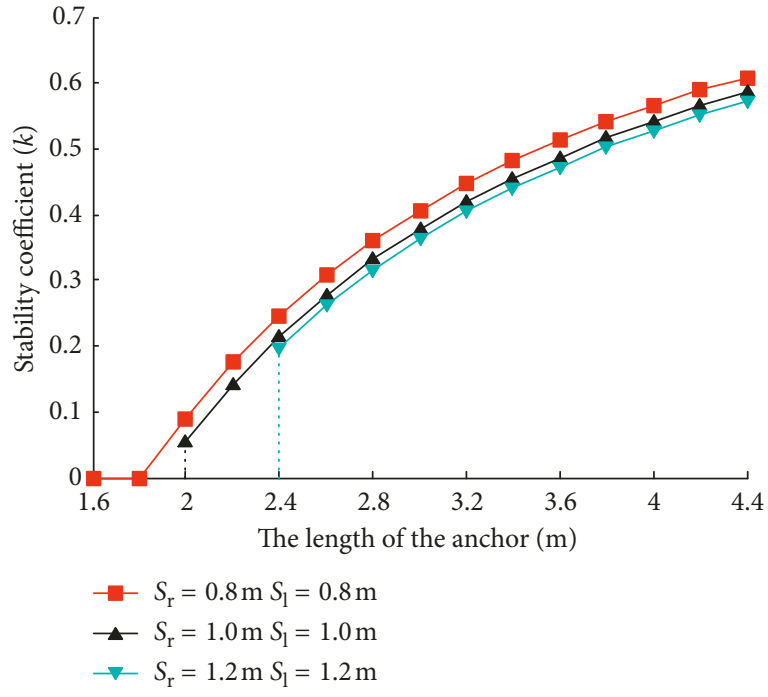

FIGURE 8: Influence of the anchor length and spacing on the stability of surrounding rock.

anchor pretightening force and the anchor diameter have a significant influence on the surrounding rock stability coefficient, and the influence is relatively independent.

5.2.2. Influence of the Rock Mass Physical-Mechanical Parameters on the Surrounding Rock Stability Coefficient. Figure 10 is a graph showing the influence of the rock's physical-mechanical parameters on the surrounding rock's stability coefficient. It can be seen that as the rock mass elastic modulus decreases or the rock mass's Poisson's ratio increases, the value of $k$ decreases. The surrounding rock deforms greatly when the surrounding rock is soft, which fully exerts the support of the anchor so that the physical-mechanical parameters of the surrounding rock reinforcement body are much larger than the physical-mechanical parameters of the rock mass, thereby increasing the surrounding rock stability. However, the surrounding rock is too soft, and the deformation is too large, which may also cause the anchor to yield or the anchor support to be lost, reducing the surrounding rock stability. It can also be seen that, as the rock cohesion and internal friction angle increase, the value of $k$ increases. The value of $k$ decreases by $2.23 \%$ as the elastic modulus of the rock increases from $1 \mathrm{GPa}$ to $2 \mathrm{GPa}$. The value of $k$ increased by $8.40 \%$ as the rock's Poisson's ratio increased from 0.25 to 0.35 . The value of $k$ increased by 2.06 times as the rock cohesion increased from $1 \mathrm{MPa}$ to $2 \mathrm{MPa}$. The value of $k$ increased by 1.89 times as the internal friction angle of the rock increased from $30^{\circ}$ to $40^{\circ}$. It can be seen that the rock cohesion and internal friction angle have a great influence on the 


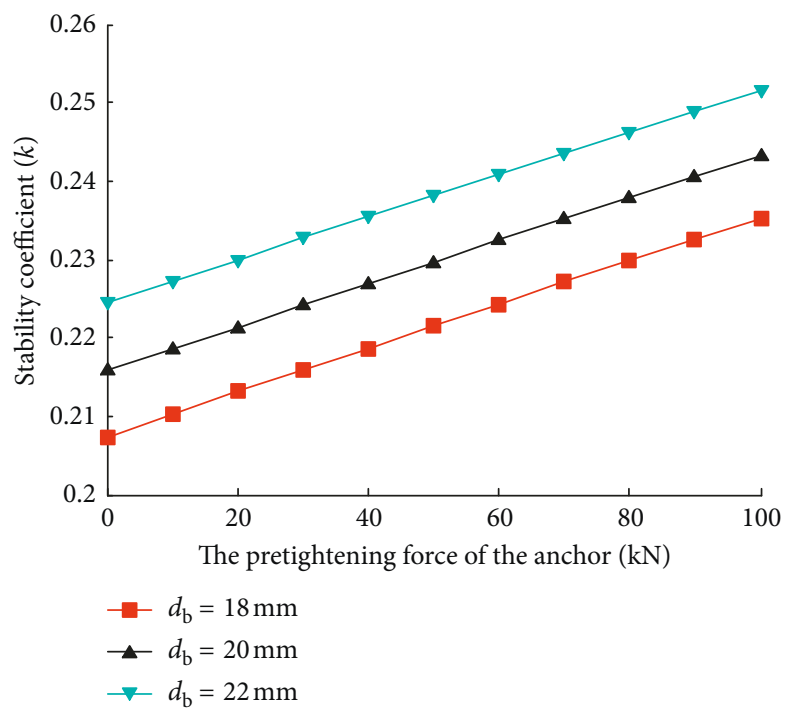

FIGURE 9: Influence of the anchor pretightening force and anchor diameter on the stability of the surrounding rock.

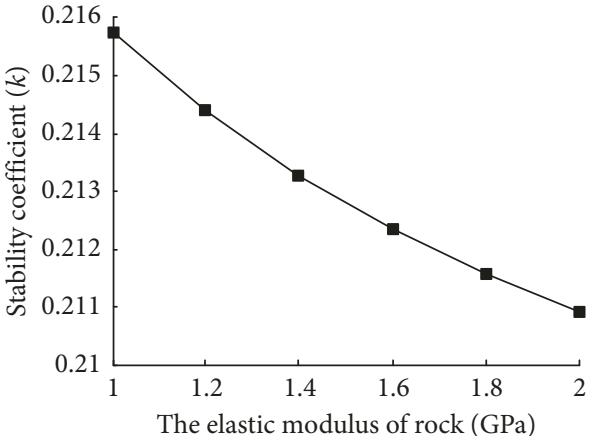

(a)

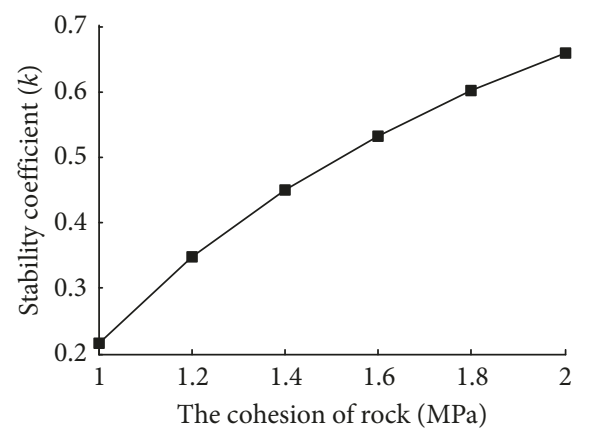

(c)

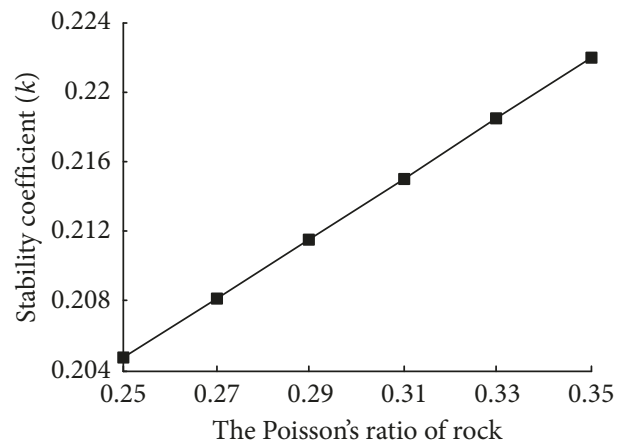

(b)

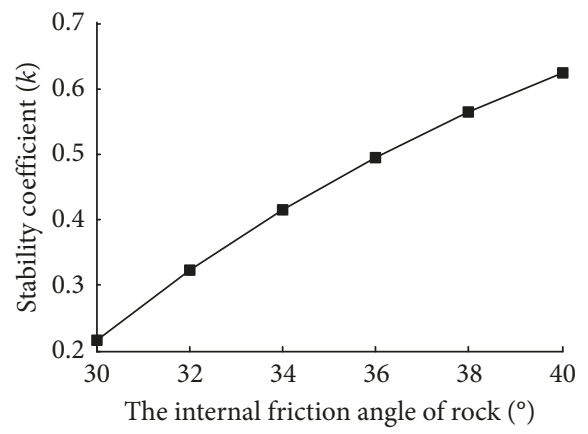

(d)

Figure 10: Influence of the rock's physical-mechanical parameters on the stability of the surrounding rock: (a) elastic modulus; (b) Poisson's ratio; (c) cohesion; (d) internal friction angle.

stability of the surrounding rock, but the rock's elastic modulus and Poisson's ratio have little influence on the stability of the surrounding rock.

5.2.3. Influence of the Rock's Dilatancy Angle and Intermediate Principal Stress on the Surrounding Rock Deformation. Figure 11 is a graph showing the influence of the rock mass's dilatancy angle and the intermediate principal stress on the surrounding rock deformation. It can be seen that, as the intermediate principal stress coefficient increases, the radius of the surrounding rock reinforcement body damage zone and the displacement of the tunnel wall decrease. The larger the $b$ is, the flatter the $k$ curve is. As the dilatancy angle increases, the radius of the surrounding rock reinforcement body damage zone remains the same, and the displacement of the tunnel wall increases. It can also be seen that the greater the intermediate principal stress coefficient, 


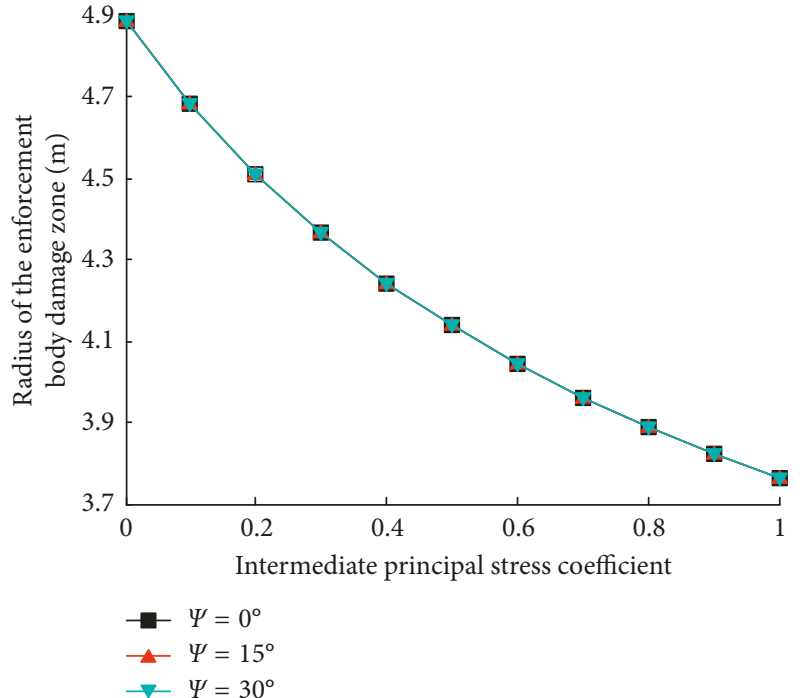

(a)

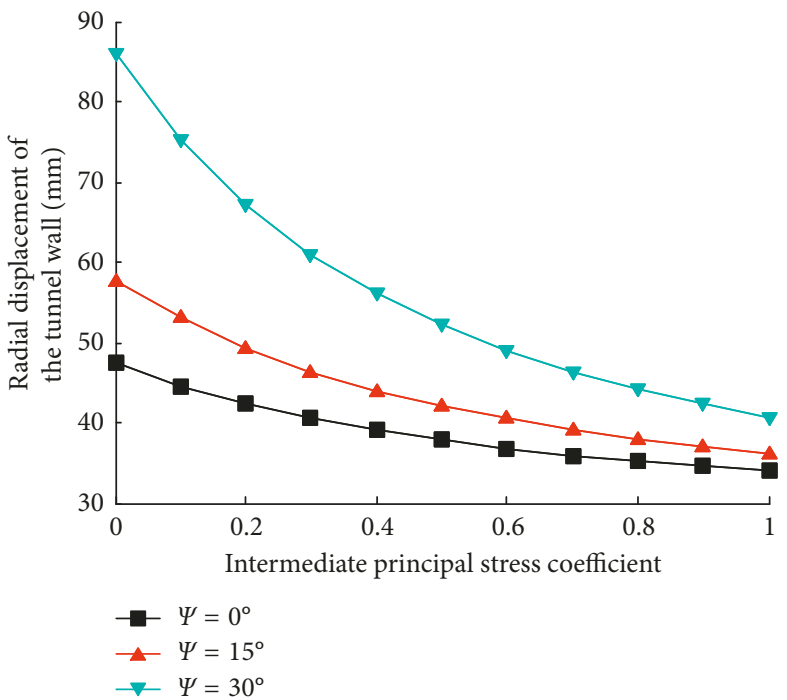

(b)

FIGURE 11: Influence of the rock's dilatancy angle and intermediate principal stress on the surrounding rock deformation: (a) radius of the surrounding rock reinforcement body damage zone; (b) radial displacement of the tunnel wall.

the less the influence of the dilatancy angle on the surrounding rock deformation. When the influence of the dilatancy angle is not considered, as the intermediate principal stress coefficient increases from 0 to 1 , the radius of the surrounding rock reinforcement body damage zone reduces by $22.95 \%$, and the displacement of the tunnel wall reduces by $28.48 \%$.

5.3. Comparison with Existing Theoretical Results. In order to further verify the rationality and superiority of the theory, the parameters used in the calculation and analysis are taken from the examples used in the articles of Park [34] and Ogawa [35], which have a certain contrast. Substituting the above relevant parameters into the derivation formulas of Sections 3 and 4 , when the radius of the tunnel is $2 \mathrm{~m}$, the radius of the plastic zone is $3.921 \mathrm{~m}$, and the displacement of the tunnel surface is the largest, which is $5.347 \mathrm{~mm}$. The results of this paper are compared with the results of the four authors of Park and Kim [34], Ogawa and Lo [35], Reed [36], and Meng et al. [20], as shown in Table 5.

It can be seen from Table 5 that when there is no anchor support, the plastic zone radius calculated in this paper is consistent with the results of Meng and Park, and both are close to the results of $\mathrm{FLAC}^{3 \mathrm{D}}$ numerical simulation, while the plastic zone radius of the Ogawa and Reed is slightly smaller. The displacement of the cave wall calculated in this paper is close to that of Meng. The calculation result of Park is larger, the calculation result of Ogawa is second, and the displacement results in this paper are the smallest. The reason why the Park displacement result is large is that the hydrostatic pressure value is subtracted from the stress portion when calculating the elastic portion of the strain in the plastic zone. When Ogawa calculates the elastic part of the strain in the plastic zone, the calculation formula of the hoop strain is wrong. In Table 5, the displacement of the plastic zone calculated in this paper is close to that obtained by Meng and Reed, but the radius of the plastic zone obtained by the latter is larger than that of this paper. The reason is that Reed considers the compressive strength of the rock after yield reduction and does not consider the decrease in the gradient $f$ in the principal stress space, while Meng accounts for the cohesion and internal friction angle decreasing.

When there is an anchor support, the displacement of the cave wall calculated in this paper is $16.523 \mathrm{~mm}$, and the displacement of the cave wall calculated by Meng is $17.238 \mathrm{~mm}$. The calculation result in this paper is slightly smaller than that of Meng. The reason is that when the physicomechanical parameters of the anchored rock mass are calculated in this paper, the mechanical coupling effect between the anchor and the surrounding rock is considered. However, Meng only averages the surrounding rock parameters and anchor parameters by area to obtain the physical and mechanical parameters of the composite. Therefore, the calculation process of this paper considers the coordinated deformation of the anchor and the surrounding rock, and the calculation result is closer to the actual situation.

\section{Conclusions}

(1) Using the idea of homogenization, the composite of the anchor and the anchored rock mass is regarded as a supporting structure, which is defined as the surrounding rock reinforcement body. A method of the surrounding rock reinforcement body support is proposed, and a mechanical model of the coordinated deformation of the surrounding rock reinforcement body and deep rock mass is established.

(2) By analyzing the mutual coupling effect between the wholly grouted anchor and the anchored rock mass, 
TABLE 5: Comparison of results from different authors.

\begin{tabular}{|c|c|c|c|c|c|c|}
\hline & $\begin{array}{l}\text { Park and } \\
\text { Kim [34] }\end{array}$ & $\begin{array}{c}\text { Ogawa and } \\
\text { Lo [35] }\end{array}$ & Reed [36] & FLAC $^{3 D}$ & $\begin{array}{c}\text { Meng } \\
\text { et al. [20] }\end{array}$ & $\begin{array}{l}\text { This } \\
\text { paper }\end{array}$ \\
\hline Wall displacement without anchor support (mm) & 50.233 & 23.902 & 17.885 & 64.090 & 17.238 & 16.523 \\
\hline Wall displacement with anchor support (mm) & - & - & - & 4.545 & 5.696 & 5.347 \\
\hline $\begin{array}{l}\text { Plastic zone radius of surrounding rock without } \\
\text { anchor support }(\mathrm{m})\end{array}$ & 5.561 & 5.509 & 4.697 & 5.500 & 5.561 & 5.506 \\
\hline $\begin{array}{l}\text { Plastic zone radius of surrounding rock with anchor } \\
\text { support }\end{array}$ & - & - & - & 3.000 & 4.028 & 3.921 \\
\hline
\end{tabular}

the expression of the physical-mechanical parameters of the surrounding rock reinforcement body is derived. After the elastoplastic analysis of the mechanical model is conducted, the stress and displacement expressions of the surrounding rock are derived, and the displacement of the tunnel wall, the radius of the surrounding rock reinforcement body damage zone, and the maximum axial force of the anchor are obtained. A method for evaluating the stability of surrounding rock by the degree of damage of the surrounding rock reinforcement body is proposed, and the stability coefficient of surrounding rock is also defined.

(3) Research presented in this paper shows that the anchor support increases the elastic modulus and cohesion of the surrounding rock by $0.67 \%$ and $7.70 \%$, respectively, and reduces the Poisson's ratio of the surrounding rock by $1.00 \%$. The anchor support has the greatest influence on the cohesion of the surrounding rock reinforcement body. Under different support schemes, the theoretical calculations agree well with the numerical simulation results, and the difference from the actual monitoring values is less than $10 \%$, which verifies the rationality of the surrounding rock reinforcement body theory and shows the accuracy of the method.

(4) Research presented in this paper also shows that, to control the stability of surrounding rock, the design of the anchor length and spacing should follow the principle of long but sparse and short but dense. However, when the length of the anchor increases to a certain value or the anchor spacing reduces to a certain value, the surrounding rock stability coefficient changes little. Therefore, the parameter optimization of the length and spacing of the anchor should be considered to save the amount of anchors and avoid material waste. The pretightening force of the anchor and the surrounding rock stability coefficient show a linear change law, and its law is not affected by other anchor parameters. However, when the pretightening force increases to a certain value, the anchor loses the supporting effect due to yielding.

(5) The cohesion and internal friction angle of rock have a great influence on the stability of surrounding rock, but the elastic modulus and Poisson's ratio of the rock mass have little influence on the stability of surrounding rock. The larger the intermediate principal stress value is, the better the self-supporting capacity of surrounding rock is, which is beneficial for optimizing the anchor support parameters and reducing the support cost. However, the displacement of the tunnel wall and the axial force of the anchor increase sharply as the dilatancy angle of surrounding rock increases, which may cause the anchor to yield and lose its supporting effect, so it is necessary to increase the support strength to ensure the surrounding rock's stability. Therefore, when designing anchor support parameters and evaluating the surrounding rock's stability, the dilatancy characteristics and intermediate principal stress effects of the surrounding rock should be comprehensively considered.

(6) Through comparison with numerical simulation, field measurement, and existing theory, the theory and calculation method of this paper are more suitable for actual working conditions. It can provide a theoretical reference for further understanding the reinforcement mechanism of the anchor, provide a new method for the support design of bolts, and quantitatively evaluate the stability of the roadways under the reinforcement of the anchors.

\section{Data Availability}

The data used to support the findings of this study are available from the corresponding author upon request.

\section{Conflicts of Interest}

The authors declare that they have no conflicts of interest.

\section{Acknowledgments}

This work was financially supported by projects (no. 51508462 and 11402195) supported by the National Natural Science Foundation of China and a project (no. 2013JK0961) supported by the Shaanxi Provincial Department of the Education Funding Project.

\section{References}

[1] C. Q. Zhang, G. J. Cui, H. Zhou et al., "Experimental study on shear and deformation characteristics of the rod-grout interface," Chinese Journal of Rock Mechanics and Engineering, vol. 37, no. 4, pp. 820-828, 2018, in Chinese.

[2] T. J. Freeman, "The behaviour of fully-bonded rock bolts in the Kielder experimental tunnel," Tunnels and Tunnelling, vol. 10, no. 5, pp. 37-40, 1978. 
[3] X. G. Zhu, Q. Yang, and M. T. Luan, "Study of reinforcement mechanics for fully grouting rock bolt in tunneling wall rock," Rock and Soil Mechanics, vol. 28, no. 1, pp. 173-177, 2007, in Chinese.

[4] X. C. Yao, N. Li, and Y. S. Chen, "Theoretical solution for shear stresses on interface of fully grouted bolt in tunnels," Chinese Journal of Rock Mechanics and Engineering, vol. 24, no. 13, pp. 2272-2276, 2005, in Chinese.

[5] B. S. Zhou, B. T. Wang, C. Y. Liang et al., "Study on load transfer characteristics of wholly grouted bolt," Chinese Journal of Rock Mechanics and Engineering, vol. 36, no. 1, pp. 3774-3780, 2017, in Chinese.

[6] Y. Cai, Y. Jiang, I. Djamaluddin, T. Iura, and T. Esaki, “An analytical model considering interaction behavior of grouted rock bolts for convergence-confinement method in tunneling design," International Journal of Rock Mechanics and Mining Sciences, vol. 76, pp. 112-126, 2015.

[7] J. R. Zhang and B. F. Tang, "Hyperbolic function model to analyze load transfer mechanism on bolts," Chinese Journal of Geotechnical Engineering, vol. 24, no. 2, pp. 188-192, 2002, in Chinese.

[8] F. F. Ren, Z. J. Yang, J. F. Chen, and W. W. Chen, "An analytical analysis of the full-range behaviour of grouted rockbolts based on a tri-linear bond-slip model," Construction and Building Materials, vol. 24, no. 3, pp. 361-370, 2010.

[9] M. H. Huang, Z. Zhou, and J. P. Ou, "Nonlinear full-range analysis of load transfer in fixed segment of tensile anchors," Rock Mechanics and Engineering, vol. 33, no. 11, pp. 21902199, 2014, in Chinese.

[10] P. S. Zhang and K. Yin, "The whole process of force transmission mechanism of tensile type anchor section analysis method," Journal of Underground Space and Engineering, vol. 5, no. 4, pp. 716-723, 2009, in Chinese.

[11] X. G. Zheng, N. Zhang, and F. Xue, "Study on stress distribution law in anchoring section of prestressed bolt," Journal of Mining \& Safety Engineering, vol. 29, no. 3, pp. 366-368, 2012, in Chinese.

[12] C. N. You, Y. B. Zhan, Q. Y. Liu et al., "Shear lag-debonding model for anchorage section of prestressed anchor cable," Chinese Journal of Rock Mechanics and Engineering, vol. 32, no. 4, pp. 801-805, 2013, in Chinese.

[13] H. Zhou, R. C. Xu, C. Q. Zhang et al., "Research on effect of interior bonding section length of prestressed anchor rod," Rock and Soil Mechanics, vol. 36, no. 5, pp. 2688-2694, 2015, in Chinese.

[14] Y. Fang and C. He, "Study on the interaction of whole bonded rock bolt and tunnel surrounding rock," Engineering $\mathrm{Me}$ chanics, vol. 24, no. 6, pp. 111-116, 2007, in Chinese.

[15] J. Z. Wen, Y. X. Zhang, and C. Wang, "Study of mechanical model of fully grouted rock bolt's anchorage interface in tunnel surrounding rock," Rock and Soil Mechanics, vol. 34, no. 6, pp. 1645-1651, 2013, in Chinese.

[16] H. Zhou, M. Xiao, and J. T. Chen, "Study of anchoring mechanism and analysis of anchoring effect of fully grouted rock anchor in large-scale underground caverns," Rock and Soil Mechanics, vol. 37, no. 5, pp. 1503-1511, 2016, in Chinese.

[17] S. Pelizza, S. H. Kim, and J. S. Kim, "A study of strength parameters in the reinforced ground by rock bolts," in Proceedings of World Tunnel Congress and 32nd ITA Assembly, pp. 6-385, Seoul, South Korea, April 2006.

[18] S. S. Yang and B. S. Zhang, "The influence of bolt action force to the mechanical property of rocks," Rock and Soil Mechanics, vol. 24, no. 10, pp. 280-282, 2003, in Chinese.
[19] A. Bobet and H. H. Einstein, "Tunnel reinforcement with rockbolts," Tunnelling and Underground Space Technology, vol. 26, no. 1, pp. 100-123, 2011.

[20] Q. Meng, H. B Zhao, Z. L. Ru et al., "Analytical solution for circular tunnels with rock bolts," Engineering Mechanics, vol. 32, no. 7, pp. 17-25, 2015, in Chinese.

[21] Q. Yan, S. C. Li, C. Xie et al., "Analytical solution for ground characteristic curve of composite rock mass reinforced by bolts in circular tunnels," Chinese Journal of Rock Mechanics and Engineering, vol. 36, no. 12, pp. 3021-3027, 2017, in Chinese.

[22] Q. Zhang, S. L. Wang, and X. R. Ge, "Elastoplastic analysis of circular openings in strain-softening rock masses," Chinese Journal of Rock Mechanics and Engineering, vol. 29, no. 5, pp. 1031-1035, 2010, in Chinese.

[23] G. Y. Hou and X. S. Niu, "Perfect elastoplatic solution of axisymmetric cylindrical cavity based on levy-mie contitutive relation and Hoek-Brown failure criterion," Chinese Journal of Rock Mechanics and Engineering, vol. 29, no. 4, pp. 765-777, 2010, in Chinese.

[24] S. Wen and S. Q. Yang, "Study of deformations of surrounding rock of tunnel based on Hoek-Brown criterion," Rock and Soil Mechanics, vol. 32, no. 1, pp. 63-69, 2011, in Chinese.

[25] D. M. Yu, Y. F. Fan, J. X. Duan et al., "Elastoplastic unified solutions to deep-buried circular tunnels considering intermediate principal stress," Journal of Shanghai Jiao Tong University, vol. 47, no. 9, pp. 1447-1453, 2013, in Chinese.

[26] Z. Q. Liu and D. M. Yu, "Elastoplastic stress and displacement analytical solutions to deep-buried circular tunnels considering intermediate principal stress and dilatancy," Engineering Mechanics, vol. 29, no. 8, pp. 289-296, 2012, in Chinese.

[27] J. L. Pan, Z. N. Gao, Z. W. Zheng et al., "Elasto-plastic analysis on surrounding rock of roadway considering damage, shear dilation and intermediate principal stress," Journal of Safety Science and Technology, vol. 13, no. 2, pp. 40-45, 2017, in Chinese.

[28] J. J. Wei, "Elastic-plastic analysis of surrounding rocks considering material dilatancy and softening," Journal of Civil, Architectural \& Environmental Engineering, vol. 35, no. 3, pp. 7-11, 2013, in Chinese.

[29] S. C. Gu and P. Zhou, "Analysis on bolt support mechanism and surrounding rock stability control of roadway under complex conditions," Electronic Journal of Geotechnical Engineering, vol. 23, no. 3, pp. 565-578, 2018.

[30] Q. Yang, X. G. Zhu, and M. T. Luan, "Development of hyperbolic model for fully grouting rock bolt and parameters analysis for anchoring effect," Chinese Journal of Rock Mechanics and Engineering, vol. 26, no. 4, pp. 692-698, 2007, in Chinese.

[31] H. Oda, M. L. Zhang, and M. Skimayanma, "Study on loaddispersive anchorage and shear stress in surrounding soils," in Proceedings of International conference on Application and Development of Rock-Soil Anchoring Technology, pp. 237-244, Liuzhou, China, 1997.

[32] X. L. Ding, Q. Sheng, J. Han et al., "Numerical simulation testing study on reinforcement mechanism of prestressed anchorage cable," Chinese Journal of Rock Mechanics and Engineering, vol. 21, no. 7, pp. 980-988, 2002, in Chinese.

[33] S. J. Wei and P. F. Gou, "Analogy simulation test on strengthening effect for pretention of bolts on anchorage 
body," Journal of China Coal Society, vol. 37, no. 12, pp. 1987-1993, 2012, in Chinese.

[34] K.-H. Park and Y.-J. Kim, "Analytical solution for a circular opening in an elastic-brittle-plastic rock," International Journal of Rock Mechanics and Mining Sciences, vol. 43, no. 4, pp. 616-622, 2006.

[35] T. Ogawa and K. Y. Lo, "Effects of dilatancy and yield criteria on displacements around tunnels," Canadian Geotechnical Journal, vol. 24, no. 1, pp. 100-113, 1987.

[36] M. B. Reed, "Stresses and displacements around a cylindrical cavity in soft rock," IMA Journal of Applied Mathematics, vol. 36, no. 1, pp. 223-245, 1986. 


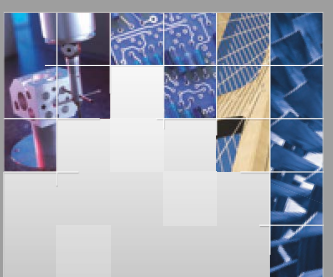

\section{Enfincering}
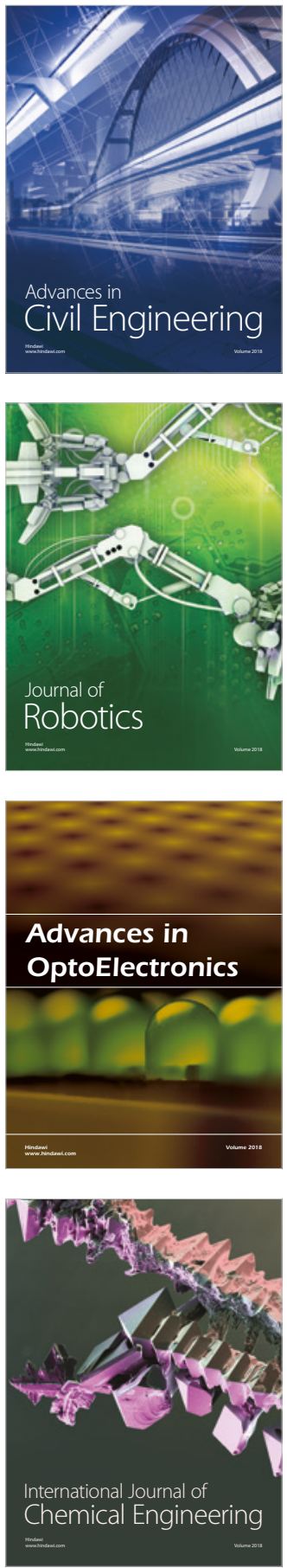

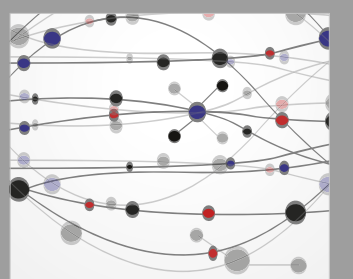

\section{Rotating \\ Machinery}

The Scientific World Journal

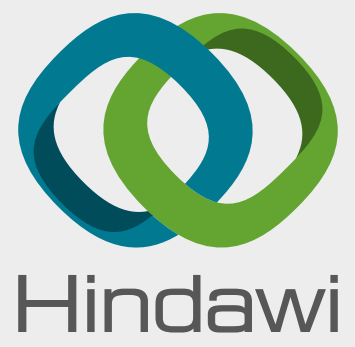

Submit your manuscripts at

www.hindawi.com
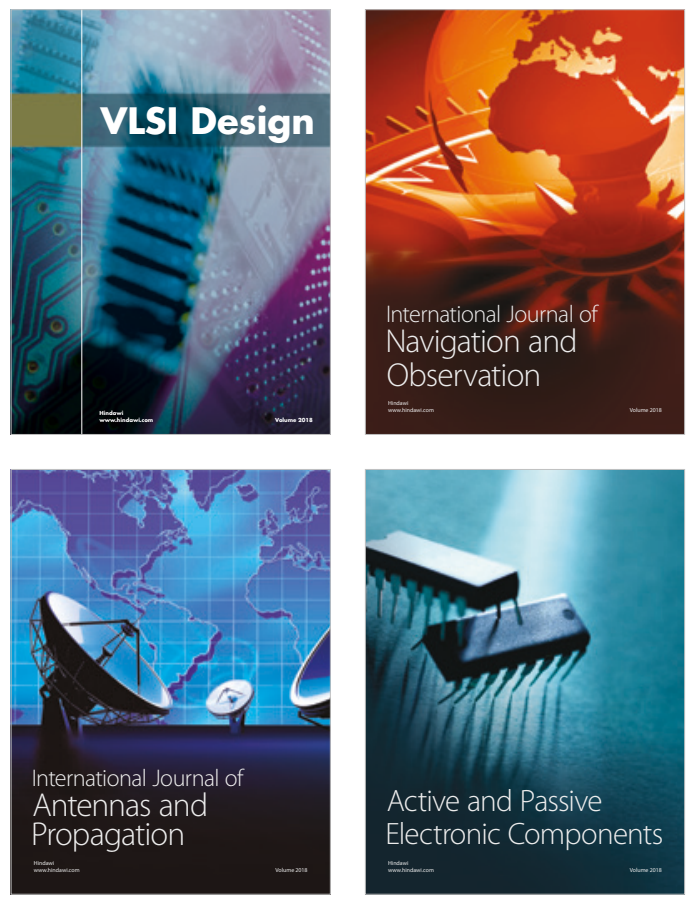
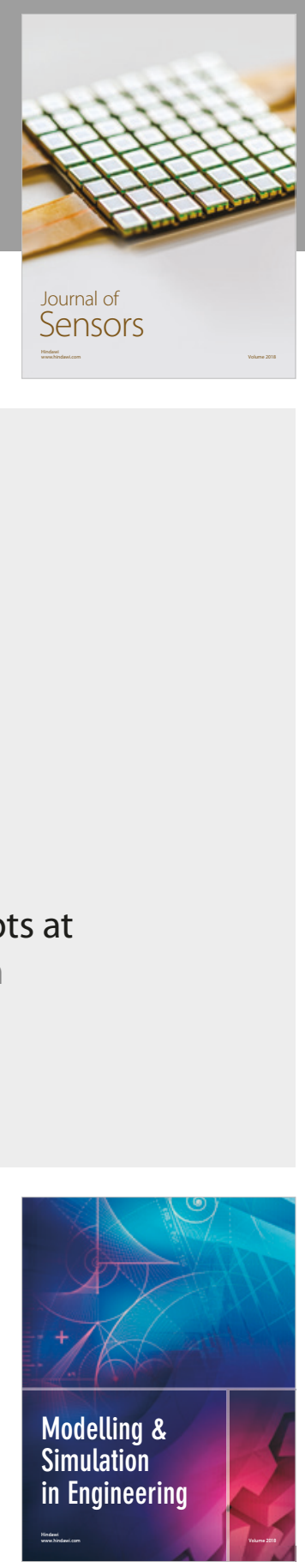

\section{Advances \\ Multimedia}
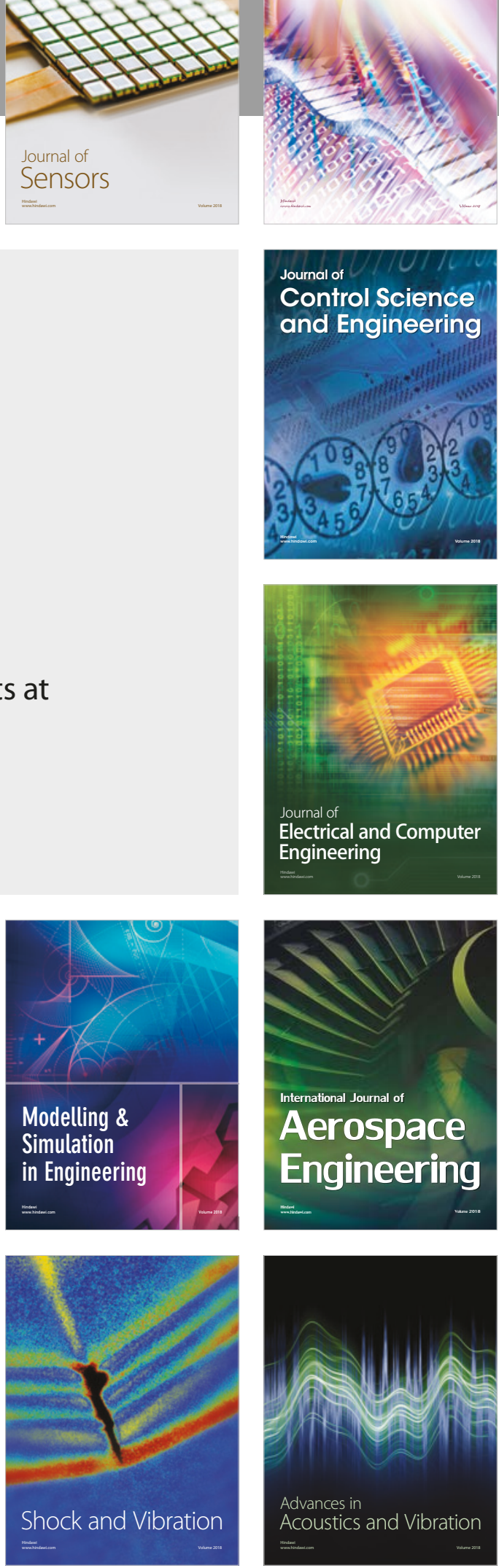